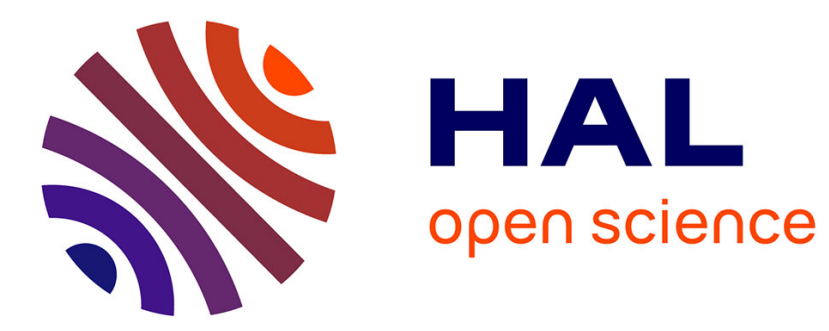

\title{
Calcium isotopic variability of cervid bioapatite and implications for mammalian physiology and diet
}

\author{
A. Hassler, J. E. Martin, G. Merceron, M. Garel, V. Balter
}

\section{To cite this version:}

A. Hassler, J. E. Martin, G. Merceron, M. Garel, V. Balter. Calcium isotopic variability of cervid bioapatite and implications for mammalian physiology and diet. Palaeogeography, Palaeoclimatology, Palaeoecology, 2021, 573, pp.110418. 10.1016/j.palaeo.2021.110418 . hal-03423969

\section{HAL Id: hal-03423969 https://hal.science/hal-03423969}

Submitted on 10 Nov 2021

HAL is a multi-disciplinary open access archive for the deposit and dissemination of scientific research documents, whether they are published or not. The documents may come from teaching and research institutions in France or abroad, or from public or private research centers.
L'archive ouverte pluridisciplinaire HAL, est destinée au dépôt et à la diffusion de documents scientifiques de niveau recherche, publiés ou non, émanant des établissements d'enseignement et de recherche français ou étrangers, des laboratoires publics ou privés. 
1 This is an early version. Substantial changes in the content are available from the

2 definitive version: https://doi.org/10.1016/j.palaeo.2021.110418

3 Calcium isotopic variability of cervid bioapatite and implications for mammalian 4 physiology and diet

5 A. Hassler ${ }^{1 *}$ (auguste.hassler@ens-lyon.fr), J.E. Martin ${ }^{1}$ (jeremy.martin@ens-lyon.fr), G.

6 Merceron ${ }^{2}$ (gildas.merceron@univ-poitiers.fr), M. Garel ${ }^{3}$ (mathieu.garel@,ofb.gouv.fr), V.

$7 \quad$ Balter $^{1}$ (vincent.balter@ens-lyon.fr)

8 'Univ. Lyon, ENS de Lyon, Université Claude Bernard Lyon 1, CNRS, UMR 5276

9 Laboratoire de Géologie de Lyon : Terre, Planètes, Environnement, F-69007 46 Allée d'Italie, 10 Lyon, France

11 22Laboratoire de Paléontologie, Évolution, Paléoécosystèmes, Paléoprimatologie 12 (PALEVOPRIM; ex-iPHEP), UMR 7262 CNRS \& Université de Poitiers, 86073 Poitiers 13 Cedex 9, France

$14{ }^{3}$ Unité Ongulés Sauvages, Office Français de la Biodiversité (OFB; ex-ONCFS), 5 allée de 15 Bethléem, Z.I. Mayencin, F-38610 Gières, France

$16 *$ corresponding author

\section{Abstract}

There is clues that calcium $(\mathrm{Ca})$ isotope composition of vertebrate bioapatite is 19 influenced by diet and trophic level. These clues however conflict with several cases of

20 mammal species exhibiting $\mathrm{Ca}$ isotope compositions which are inconsistent with their trophic

21 levels. These observations support that diet may not be the only factor driving the Ca isotope

22 composition in mammalian enamel and bone. To investigate this question, we selected a 
modern Cervus elaphus population (Bauges Natural Regional Park, Alps, France) to serve as

24 a model for $\mathrm{Ca}$ isotope physiology of cervids and other mammals. Subsequently, we 25 reinvestigated the case of the fossil Rangifer tarandus population from Jaurens (Late

26 Pleistocene locality, 32.6 to $29.7 \mathrm{kyr} \mathrm{BP}$, France), a population for which abnormal ${ }^{44} \mathrm{Ca}-$ 27 depleted isotope compositions have been previously documented. By combining bone 28 samplings and serial enamel micro-samplings, we discuss the main potential sources of $\mathrm{Ca}$ 29 isotopic variability in bioapatite of young and adult individuals. This includes the effects of 30 gestation, lactation, antlerogenesis, browser-grazer ecologies, osteophagia and natural mineral

31 licks. Our results highlight an important effect of lactation on bone Ca isotope composition $32\left(\delta^{44 / 42} \mathrm{Ca}=+0.18 \pm 0.07 \% ; 95 \%\right.$ confidence interval $)$, whereas other factors such as gestation 33 or antlerogenesis seem more secondary. Our enamel micro sampling method allowed to detect 34 when enamel $\mathrm{Ca}$ isotope composition could be affected by milk consumption or mineral 35 supplementation. Thanks to these advances, we collected new data from the Pleistocene 36 reindeers of Jaurens which are now consistent with their apparent low trophic level 37 (corresponding to a herbivorous diet). This demonstrates that disentangling ecological and 38 physiological signals within enamel $\mathrm{Ca}$ isotope compositions is possible by using serial 39 micro-sampling. This approach allows retrieving accurate trophic information from this proxy 40 and which, altogether, truly push forward the limits of $\mathrm{Ca}$ isotope applications regarding 41 paleoecology, physiology and ethology.

\section{Keywords}

43 Stable isotopes; Geochemistry; Paleoecology; Lactation, Mineral supplementation; Mammal 44 physiology 


\section{Introduction}

An increasing number of studies suggest that the stable Ca isotope composition of the hydroxylapatite of vertebrate bone and teeth, represents a record of diet within modern and fossil skeletal remains (Clementz et al., 2003; Chu et al., 2006; Reynard et al., 2010; Heuser et al., 2011; Clementz, 2012; Martin et al., 2015, 2017a, 2017b, 2018; Hassler et al., 2018). Body $\mathrm{Ca}$ originates mainly from food and water for land animals, but the $\mathrm{Ca}$ isotope composition of animals diverges from their food. At the opposite of carbon and nitrogen patterns, heavy $\mathrm{Ca}$ isotopes are discriminated against light $\mathrm{Ca}$ isotopes during their routing from food to tissues, notably in bone and enamel (Skulan and DePaolo, 1999; Chu et al., 2006; Hirata et al., 2008; Tacail et al., 2014; Heuser, 2016; Heuser et al., 2016). This results in a trophic level effect (hereafter TLE) with bones of herbivorous animals exhibiting more ${ }^{44} \mathrm{Ca}$-depleted compositions compared to the plants they consume, and carnivorous predators following the same trend compared to their preys. This ultimately leads to an isotopic clustering of animal taxa in function of their trophic level, with primary consumers exhibiting a heavier $\mathrm{Ca}$ isotope composition than tertiary consumers, and secondary consumers exhibiting an intermediate isotopic composition. This has been observed in land ecosystems (Chu et al., 2006; Reynard et al., 2010; Martin et al., 2017a, 2018; Hassler et al., 2018; Dodat et al., 2021) and marine ecosystems (Clementz et al., 2003; Clementz, 2012; Martin et al., $2015,2017 b$ ), even though for marine animals the Ca originating from seawater likely buffers dietary $\mathrm{Ca}$ intakes. These studies are based on ${ }^{44} \mathrm{Ca} /{ }^{42} \mathrm{Ca}$ or ${ }^{44} \mathrm{Ca} /{ }^{40} \mathrm{Ca}$ analyses of the hydroxylapatite of bone and teeth, commonly expressed as $\delta^{4 / 40} \mathrm{Ca}$ and $\delta^{44 / 40} \mathrm{Ca}$, respectively (equivalent to the variation in \%o compared to the $\mathrm{Ca}$ isotope ratios of a reference material,

further detailed in section 2.6). Moreover, this technic allows to study the ecology of both modern and fossil specimens thanks to the good preservation potential of such mineralized 
69 tissues and their $\mathrm{Ca}$ (Heuser et al., 2011; Martin et al., 2017a). This body of studies supports 70 that $\mathrm{Ca}$ isotopes are a promising tool for diet and trophic inferences in modern and 71 paleontological contexts with a large temporal range of action, providing the fact that

72 mineralized tissues are preserved. However, inferring a TLE within mammalian communities 73 relies on first order observations of $\mathrm{Ca}$ isotopic variability among predators and their preys. 74 As highlighted in previous work, many uncertainties remain concerning the mechanisms 75 behind fractionation processes as related to physiology versus environmental sources. As 76 such, not all taxa are strictly following the theoretical isotopic/trophic clustering in the faunas 77 studied so far. For some specific faunas and trophic niches, diet seems hard to constrain with $78 \mathrm{Ca}$ isotopes only (Reynard et al., 2010; Melin et al., 2014). Moreover, bone or enamel Ca 79 isotope compositions sometime overlap between herbivores and predators, with herbivores 80 occasionally exhibiting isotope compositions more ${ }^{44} \mathrm{Ca}$-depleted than predators from the 81 same fauna (e.g. hippopotamidae, mammoths and cervidae; see Martin et al., 2017a, 2018;

82 Dodat et al., 2021). This raises important questions about what can generate such issues, and 83 highlights how critical it is for the accurate use of this proxy to reconcile the evidences of 84 TLE with the occasional decoupling recorded between trophic level and Ca isotope 85 compositions.

The isotopic offset between diet and bone which generates the TLE $\left(\Delta^{44 / 42} \mathrm{Ca}_{\text {diet-bone }}\right)$ is 87 relatively constant among mammal species with a value of $-0.54 \pm 0.08 \%$ o ( 2 standard error, 8820 individuals from 6 mammal species; reviewed in Tacail (2017)), despite resulting from the 89 combination of numerous body $\mathrm{Ca}$ fluxes associated with $\mathrm{Ca}$ isotope fractionation (Skulan 90 and DePaolo, 1999; Chu et al., 2006; Hirata et al., 2008; Tacail et al., 2014; Heuser et al., 91 2016; Tacail, 2017). The most impactful fluxes identified so far are the kidney Ca 92 reabsorption from primary urines (Skulan et al., 2007; Heuser and Eisenhauer, 2010; Morgan 
et al., 2012; Tacail et al., 2014; Channon et al., 2015; Heuser et al., 2016, 2019; Eisenhauer et al., 2019), the milk production and excretion (Chu et al., 2006; Reynard et al., 2010) and the bone mineralization (Skulan and DePaolo, 1999; Skulan et al., 2007; Heuser and Eisenhauer, 2010; Reynard et al., 2010; Morgan et al., 2012; Channon et al., 2015), although the significance of this last has been recently questioned (Tacail, 2017; Tacail et al., 2020). Changing these fluxes, like during gestation, lactation (Ramberg Jr et al., 1970; Cross et al., 1995; Giesemann et al., 1998; Karlsson et al., 2001; Wysolmerski, 2002; Vanhouten and Wysolmerski, 2003; Gallego et al., 2006; Kovacs and Fuleihan, 2006; Tacail, 2017) or antlerogenesis (Mitchell et al., 1976; Muir et al., 1987a, 1987b), likely modify the Ca isotopic equilibrium of the organism, the resulting $\Delta^{44 / 42} \mathrm{Ca}_{\text {diet-bone }}$ offset, and could generate TLE discrepancies. Alternatively, the consumption of milk during nursing can also generate TLE discrepancies by changing the diet $\mathrm{Ca}$ isotope composition of non-weaned individuals compared to weaned individuals (Chu et al., 2006; Li et al., 2016, 2020; Tacail et al., 2017, 2019). Finally, Ca enriched mineral supplementation such as with mineral licks and osteophagia, as well as the $\mathrm{Ca}$ isotopic variability inherent to plants (Holmden and Bélanger, 2010; Gussone and Heuser, 2016; Schmitt, 2016; Moynier and Fujii, 2017; Martin et al., 2018; Griffith et al., 2020), are also able to blur the trophic clustering of $\mathrm{Ca}$ isotope compositions. The aim of this study is thus to investigate how these seven factors can affect bone and enamel $\mathrm{Ca}$ isotope compositions in modern animals, then to use this background to unravel a case study of TLE discrepancy previously documented.

We carried out the first part of this project by monitoring the bone and enamel $\mathrm{Ca}$ isotope compositions of a modern cervid population (red deer, Cervus elaphus), mainly originating from the Bauges Natural Regional Park (NRP), Alps, (Savoie, France). This modern population then served as a model to discuss TLE discrepancies, and more precisely 
117 to discuss the case of the reindeers (Rangifer tarandus) from the Pleistocene locality of 118 Jaurens (Corrèze, France). Martin et al. (2017a) showed that reindeers from this locality 119 (dated between 32.6 to 29.7 kyr BP, Guérin et al. 1979) exhibit ${ }^{44}$ Ca-depleted compositions in 120 tooth enamel down to a $\delta^{44 / 42} \mathrm{Ca}$ value of $-1.75 \pm 0.09 \%$ ( 2 standard deviation.; 3 individuals). 121 This is different from the Ca isotope compositions of the other herbivores of this locality, and 122 closer from the one of lions and wolfs (Martin et al., 2017a). In accordance with the 
141

142

\section{Material and methods}

\subsection{Modern specimens}

We studied a total of 21 specimens of wild red deer of two age classes (subadult and adult) and sex (10 males, 11 females), coming from Bauges NRP, Alps, (Savoie, France, $45.69^{\circ} \mathrm{N}, 6.14^{\circ} \mathrm{E}$ ) and slaughtered during the hunting season in 2015 (between October and November) as part of the local hunting activity. In order to identify lactation, gestation and antlerogenesis effects on the $\mathrm{Ca}$ isotope composition of mineralized tissues, we analyzed and compared the bone $\mathrm{Ca}$ isotope composition of females and males. Our two age classes allow to distinguish specimens free of strong lactation, gestation and antlerogenesis effects (two years old, referred as subadult) from the others (aged of three years or more, referred as adult). Ages of the individuals were either known thanks to population monitoring or estimated based on tooth eruption and attrition stages (Brown and Chapman, 1991a, 1991b; table S1). The reproductive status of studied females was not directly monitored, but we know from observations of the OFB (Office Français de la Biodiversité) that in the red deer population of the Bauges NRP, 80 to $100 \%$ of females aged of three years already gave birth at least once. Moreover, the OFB report that each year, about $80 \%$ of the females aged of three years or more will have a fawn. We can refine this estimation as we know the body mass of studied specimens and that fertility is strongly related to body mass in cervids. Females are usually fertile when attaining $80 \%$ of the adult body mass (Albon et al., 1986; Pellerin et al., 2014) and are around $30 \%$ heavier at the end of autumn if they did not gave birth to a fawn earlier in the year (Mitchell et al., 1976; Clutton-Brock et al., 1982). These data allow to identify females which were too puny to be fertile, and females which were suspiciously too fat to have nursed a fawn recently. At the light of these data and knowing that the Bauges NRP deer population breed quite actively, we can confidently assume that adult females 
165

166

167

168

169

170

171

172

173

174

175

176

177 an adult male with premolars P2, P3, P4, and molars M1, M2, M3 fully emerged and

178 moderately worn (specimen ID number: UP-15CE5672, lab name: AB). The second is a

179 juvenile female with deciduous premolar DP2, DP3, DP4, and molars M1, M2 fully emerged

Bone samples were collected from mandibles, previously manually cleaned and boiled prior to be integrated to the collection of the PALEVOPRIM laboratory (UMR CNRS 7262 University of Poitiers, France). For each mandible, bone sample powder was collected few centimeters under the second molar, with the help of a handheld drill (8200 Dremel equipped with a tungsten steel solid carbide bit). In order to remove any trace of dirt or other environmental contaminants, the first layer of bone surface was removed with the drill then cleaned with pure ethanol prior to sampling. Between 0.4 and $0.7 \mathrm{mg}$ of bone powder were sampled and weighted prior to chemical preparation.

Along with bone sampling and in order to investigate intra-tissue and inter-tissue $\delta^{44 / 42} \mathrm{Ca}$ variability, we selected two specimens for serial enamel micro-sampling. The first is and with an erupting M3 in ongoing mineralization (specimen ID number: UP-15CE3734, lab

181 name: JVB). The serial micro-samplings performed on these specimens provide snapshots of 182 the enamel $\mathrm{Ca}$ isotope composition at different ages, depending on when each enamel zone 183 mineralized. This ultimately allows to identify isotopic anomalies produced by milk 184 consumption, osteophagia, mineral licks or occasional consumption of ${ }^{44} \mathrm{Ca}$-depleted plants. 185 These deer specimens (AB and JVB), also had some plant leftovers trapped between their 186 teeth. We collected these rests for elemental concentration analyses. 
To assess the effect of antlerogenesis and antler consumption we selected an adult 188 male red deer preserved with its skull, mandible and antlers in the collections of the 189 Confluence Museum (Lyon, France). This specimen (ID number: MHNL-50002207, lab

\subsection{Fossil specimens}

In order to study the trophic position of reindeer from the Late Pleistocene Jaurens fauna and their peculiar $\mathrm{Ca}$ isotope composition, we selected four specimens to carry out serial enamel micro-sampling. We focused our efforts on enamel sampling instead of bones in order to limit diagenesis influence. All specimens are part of the paleontological collections of the Laboratory of Geology of Lyon (LGL-TPE, France). This includes two mandibles (one adult and one juvenile) with their associated teeth, and two isolated teeth (lower M1 and a lower DP4) from two different individuals. One of the two mandibles comes from an adult specimen with the teeth P2, P3, P4, M1, M2, M3 fully emerged and with significant tooth wear on the M1 (specimen ID number: FSL 451.409, lab name: AJ). The second mandible comes from a juvenile specimen with the teeth DP2, DP3, DP4, M1 fully emerged and with the M2 erupting (specimen ID number: FSL 451.389, lab name: JVJ). The isolated teeth are a lower left DP4 (specimen ID number: FSL 451.398, lab name: ISO DP4) and lower right M1 (specimen ID number: FSL 451.384, lab name: ISO M1), both with a minimal wear level. The lessons learned from modern specimens allow to critically discuss our new and previous (Martin et al., 2017a) enamel Ca isotope data collected on fossil reindeers from Jaurens. 


\subsection{Micro-sampling}

We designed two different procedures of serial micro-sampling. For both we use a computer-assisted micro drill device (MicroMill), allowing the sampling of $80-120 \mu \mathrm{g}$ hydroxylapatite by drilling holes of 350-400 $\mu \mathrm{m}$ wide and about $400 \mu \mathrm{m}$ depth. Teeth selected for micro-sampling were serially sampled by micro-drilling on the enamel between the apex (i.e. the top) and the neck of the tooth (i.e. the basal most enamel zone), along the growth axis of the best preserved cusp of the lingual face. The apex is mineralizing first whereas the enamel close to the neck is the last part of the enamel to mineralize. This sampling thus maximizes the studied intra-tooth time window and allows a high temporal resolution. When possible we performed serial micro-sampling using a "edge-drilling procedure". In this case, the tooth (either isolated or extracted from a mandible) was cut along the growth axis in the central part of the cusp by using a Buehler IsoMet Low Speed precision sectioning saw with a diamond-studded circular saw blade. The edge of the enamel was then polished using sandpaper with decreasing grain sizes prior to perform the micro sampling. Sampling zones were located close to the enamel-dentine junction (EDJ) in order to minimize the temporal lag between the mineralization of appositional structures and enamel maturation (Blumenthal et al., 2014; Green et al., 2017; Trayler and Kohn, 2017; Müller et al., 2019). Alternatively, when extracting and cutting teeth was impossible or when the targeted spatial sampling resolution was sufficiently low, enamel has been micro-drilled from the outer side ("outer-drilling procedure"). For this procedure, the one or two first hundreds of $\mu \mathrm{m}$ of drilled enamel were not collected, in order to collect enamel relatively close to the EDJ similarly as in the edge-drilling procedure. The choice of procedure is reported in table S1 and S2. 


\subsection{Thin section and enamel age model}

We were allowed to make thin sections on the micro sampled surface of the M1 of AB, JVB (red deer, Bauges) and ISO M1 (reindeer, Jaurens). Teeth were then sliced and polished in order to obtain $100 \mu \mathrm{m}$ thick sections. Observations in transmitted light microscopy failed to reveal neonatal lines within the enamel layers of the three M1 (AB, JVB, ISO M1), a structure observed in early mineralizing teeth of humans and other mammals that would mark birth (Klevezal and Mina, 1995; Zanolli et al., 2011; Dean et al., 2019). The age model necessary to anchor our enamel $\delta^{44 / 42} \mathrm{Ca}$ data was alternatively based on general observations made on tooth mineralization timing of red deer (Brown and Chapman, 1991b). Such data were not available for reindeer, but similarities between red deer and reindeer teeth eruption timings (Miller, 1972; Brown and Chapman, 1991b; Azorit et al., 2002) allow to use red deer data to build a coarse reindeer age model. As teeth are subject to wear, we spatially anchored our age model on the neck of teeth. The mean mineralization age of each enamel $\delta^{44 / 42} \mathrm{Ca}$ data point is then estimated based on the distance between the sampling zone and the neck of the tooth, on corresponding mineralization timings (Brown and Chapman, 1991b), and on the estimated full height of unworn teeth measured on young specimens. This method assumes a constant enamel mineralization rate along the tooth growth axis and inside tooth families. This method is thus not adapted to discuss inter-individual or intra-tooth differences in tooth mineralization rates and timings but allow for a fairly good estimation considering that enamel micro-samples average a body isotopic record spanning over a month to several months (further discussed in appendix). For studied red deers, unworn teeth displayed similar crown heights between specimens. Reindeer specimens, however, had unworn molars and premolars approximately $15 \%$ smaller than red deer, which has been considered in our age model. 


\subsection{Sample dissolution and ion chromatography}

Immediately after sampling, bone and tooth samples were transferred in Teflon beakers. All further manipulations have been done exclusively in a clean lab or under a laminar flux hood. Modern bone samples were dried with $500 \mu \mathrm{L}$ of pure ethanol evaporated at $70^{\circ} \mathrm{C}$. No attempt of leaching procedures has been carried out for fossil enamel samples, as previous $\mathrm{Ca}$ isotope analyses demonstrated no isotopic differences between leached and nonleached enamel in Jaurens samples (Martin et al., 2017a). All samples were dissolved using a mix of $1 \mathrm{ml}$ of $15 \mathrm{M}$ ultrapure nitric acid $\left(\mathrm{HNO}_{3}\right)$ and $300 \mu \mathrm{L}$ of ultrapure hydrogen peroxide (30\%). Beakers were left closed at ambient temperature for $1 \mathrm{~h}$, then were heated at $130{ }^{\circ} \mathrm{C}$ during 1 to $2 \mathrm{~h}$ more with regular degassing of nitrous fumes. When production of nitrous fumes became limited, $300 \mu \mathrm{L}$ of ultrapure hydrogen peroxide $(30 \%)$ were added and samples were left to dry down at $90{ }^{\circ} \mathrm{C}$ for few hours. The presence of organic matter was then tested using $100 \mu \mathrm{L}$ of ultrapure hydrogen peroxide $(30 \%)$. No effervescence was detected for any of the samples and solutions were thus left to dry down at $90{ }^{\circ} \mathrm{C}$. Samples selected for elemental concentration analyses were dissolved in $0.5 \mathrm{M}$ ultrapure $\mathrm{HNO}_{3}$ then split. A fraction of the solution was reserved for concentration analyses and the rest was dried down at $90{ }^{\circ} \mathrm{C}$. These dried fractions and the samples not selected for concentration analyses were kept for $\mathrm{Ca}$ isotope analyses, dissolved in $300-500 \mu \mathrm{L}$ of $6 \mathrm{M}$ ultrapure hydrochloric acid $(\mathrm{HCl})$ and dried down at $90^{\circ} \mathrm{C}$.

The chromatography procedure used for $\mathrm{Ca}$ chemical purification is derived from Tacail et al. (2014). This consist in a double column chromatography, starting with an elution on $\mathrm{AG}$ 50WX-12 resin with ultrapure $\mathrm{HCl}$, and followed by an elution on Eichrom Sr-specific resin with an ultrapure $\mathrm{HNO}_{3}$ medium. When high level of iron was suspected (e.g. fossil samples) a third column chromatography was performed, using $1 \mathrm{~mL}$ of AG1 X8 resin and 
280 281

following a procedure derived from Tacail et al. (2014). Blanks have been realized along the digestion and the chromatography, including total procedural blanks which have undergone all the steps previously described and chromatography blanks.

\subsection{Analytical procedures and nomenclature}

For more clarity within this paper, the $\mathrm{n}$ notation refers to the number of samples or specimens whereas the $n^{*}$ notation specifically refers to number of measurement replicates. The "s.d." notation refers to "standard deviation", whereas "s.e." refers to "standard error". Concentrations of major and trace elements were measured respectively on an inductively coupled plasma atomic emission spectrometer (ICP-AES) (ICAP 7400 Series, Thermo Scientific) and on an inductively coupled plasma mass spectrometer (ICP-MS) (ICAP-Q, Thermo Scientific). The reliability of measurements has been controlled through a set of blanks and reference material (SRM1486), and by replicating measures to $n^{*}=2$ for each sample.

We measured the $\mathrm{Ca}$ isotope ratios $\left({ }^{44} \mathrm{Ca} /{ }^{42} \mathrm{Ca}\right)$ using a multi-collector inductively coupled plasma mass spectrometer (MC-ICP-MS, Neptune Plus, Thermo Scientific) following the method described in Tacail et al. (2014). Prior Ca isotope analyses, Ca purified samples were dissolved and diluted in $0.05 \mathrm{M} \mathrm{HNO}_{3}$ in order to set the Ca concentration at $1.25 \mathrm{mg} . \mathrm{L}^{-1}$. This concentration matches that of the ICP Ca Lyon, our in-house bracketing reference material made of Specpure Ca plasma standard solution (Alfa Aesar) and described in previous studies (Tacail et al., 2014, 2017; Martin et al., 2015, 2017a). Unless explicit mention, the $\mathrm{Ca}$ isotope compositions reported in this article are all expressed as $\delta^{44 / 42} \mathrm{Ca}$ relatively to ICP Ca Lyon using the following formula:

$$
\delta^{44 / 42} \mathrm{Ca}=\left(\left(\left(^{44} \mathrm{Ca} /{ }^{42} \mathrm{Ca}\right)_{\text {sample }} /\left({ }^{44} \mathrm{Ca} /{ }^{42} \mathrm{Ca}\right)_{\text {ICP Ca Lyon }}\right)-1\right) \times 1000
$$


304 For easing comparisons with studies using other reference materials, $\delta^{44 / 42} \mathrm{Ca}$ ICP Ca Lyon values

305 are converted to $\delta^{44 / 42} \mathrm{Ca}_{\text {SRM915a }}$ in our tables and figures. Based on 71 measures synthetized in 306 the appendix of Martin et al. (2018), we converted $\delta^{44 / 42} \mathrm{Ca}$ ICP Ca Lyon values to $\delta^{44 / 42} \mathrm{Ca}$ SRM915a 307 values by adding $+0.518 \%$ to $\delta^{44 / 42} \mathrm{Ca}$ ICP Ca Lyon values. To express a difference of $\delta^{44 / 42} \mathrm{Ca}$ value 308 between two Ca reservoirs we use the $\Delta$ notation based on the following formula:

$$
\Delta \mathrm{x}-\mathrm{y}=\delta \mathrm{x}-\delta \mathrm{y}
$$

310 Where $\mathrm{x}$ and $\mathrm{y}$ are different Ca reservoirs. Secondary reference materials of different matrix 311 and documented $\mathrm{Ca}$ isotope composition have been used to ensure the accuracy of our 312 analytical procedure and chemical purifications. The SRM1486 cow bone meal reference material (NIST) was used in that purpose, as well as the IAPSO sea water (OSIL). The Ca

314 concentration of the blanks have also been measured with the Neptune Plus. Sample Ca 315 isotope compositions are considered different when their $\delta^{44 / 42} \mathrm{Ca}$ mean value $( \pm 2$ s.e.) do not 316 overlap. Groups of $\delta^{44 / 42} \mathrm{Ca}$ mean values are compared using Wilcoxon rank-sum tests.

\section{3. Results}

\subsection{Trueness and precision}

Chromatography and total blanks display a maximum of $70 \mathrm{ng}$ of $\mathrm{Ca}$. This is several thousand times less than the amount of $\mathrm{Ca}$ in our macro-samples (e.g. bone samples) which is 321 thus negligible. Most of our micro-samples (i.e. collected from spatial micro-sampling) 322 contained more than $6250 \mathrm{ng}$ of $\mathrm{Ca}$, and in the worst cases about $3800 \mathrm{ng}$ of $\mathrm{Ca}$. In this case 323 Ca from blanks is not completely negligible but its effect can be considered minimal. Indeed, 324 a simple mass balance calculation show that even a contamination with environmental $\mathrm{Ca}$ of extreme isotopic composition (close to seawater $\approx 0.41 \%$; Martin et al. (2015)) affecting an extremely ${ }^{44} \mathrm{Ca}$-depleted sample (e.g. $\delta^{44 / 42} \mathrm{Ca}=-2.00 \%$ ) with $3800 \mathrm{ng}$ of $\mathrm{Ca}$ would only 
generate a $+0.04 \%$ difference. This unlikely $+0.04 \%$ correspond to the maximum of contamination effect possibly expected with our blank levels for the smallest of our micro samples. Such effects can thus be neglected considering the order of magnitude of intersample differences discussed below.

The complete $\mathrm{Ca}$ isotope dataset of this study include 104 samples and reference materials for a total of 358 accurate measurements. The correlation between $\delta^{43 / 42} \mathrm{Ca}$ and $\delta^{44 / 42} \mathrm{Ca}$ values of each of these samples/reference materials follow the mass dependent relation expected for $\mathrm{Ca}$ isotope ratios (figure 1), with a slope value of $0.508 \pm 0.010$ (2 s.e) an intercept of $0.006 \pm 0.015\left(2\right.$ s.e) and a $\mathrm{R}^{2}=0.99$ (p-value $\left.<0.001\right)$. This demonstrates that no mass independent fractionation or mass specific interference has affected our measurements. Along with our different sessions of analysis, the SRM1486 exhibited a mean $\delta^{44 / 42} \mathrm{Ca}$ of $-0.99 \pm 0.13 \%$ ( 2 s.d. inter-session, $\mathrm{n}=8$ sessions $)$ with a mean intra-session 2 s.d. of $0.08 \%$ ( $n=88$ measurements). Our other secondary reference material, the IAPSO exhibited a mean $\delta^{44 / 42} \mathrm{Ca}$ of $+0.38 \pm 0.12 \%$ ( 2 s.d. inter-session, $\mathrm{n}=5$ sessions $)$ with a mean intra-session 2 s.d. of $0.06 \%$ o $(n=14$ measurements $)$. These results are both in the range of previously published data (table S3) for the SRM1486 (Heuser and Eisenhauer, 2008; Tacail et al., 2016, 2017; Martin et al., 2018) and the IAPSO (Tacail et al., 2014; Martin et al., 2015). By considering all the measurements of samples and reference materials $(n=107)$, the mean intra-sample reproducibility was of $\pm 0.07 \%$ ( 2 s.d., $\mathrm{n}=358$ measurements).

\subsection{Bone data among modern cervids}

The bone sample set from Bauges NRP display a range of $\delta^{44 / 42} \mathrm{Ca}$ between $-1.62 \pm$ $0.19 \%$ ( 2 s.d., $\left.n^{*}=3\right)$ and $-1.22 \pm 0.04 \%$ ( 2 s.d., $\left.n^{*}=2\right)$, with a mean 2 s.d. of $0.09 \%$. Females red deer have a mean bone $\delta^{44 / 42} \mathrm{Ca}$ value of $-1.36 \pm 0.24 \%$ ( 2 s.d., $\mathrm{n}=11$ ), and males a mean bone $\delta^{44 / 42} \mathrm{Ca}$ value of $-1.41 \pm 0.27 \%$ o $(2$ s.d., $\mathrm{n}=10)$. The $\delta^{44 / 42} \mathrm{Ca}$ values of 
351 female individuals are statistically indistinguishable from males when considering all age 352 classes together (Wilcoxon rank-sum test, $\mathrm{p}$-value $=0.3494$ ), but this change when considering adult specimens only (Wilcoxon rank-sum test, $\mathrm{p}$-value $=0.0499$ ). Isolating

354 females who gave birth during the last birth season from the other females allows for an even 355 clearer distinction (figure 2). These six females (later referred as lactating hinds or females) 356 display bone $\delta^{44 / 42} \mathrm{Ca}$ values higher of $+0.23 \pm<0.01 \%$ (95\% confidence interval) compared 357 to the two adult females who did not reproduce recently (later referred as yeld hinds), and differ significantly from adult males (Wilcoxon rank-sum test, p-value $<0.01$; figure 3 ) with a mean bone $\delta^{44 / 42} \mathrm{Ca}$ value higher of $+0.17 \pm 0.10 \%$ ( $95 \%$ confidence interval). The three subadult females display a range of bone $\delta^{44 / 42} \mathrm{Ca}$ values which overlap with both lactating and 361 yeld adult hinds, with the heaviest subadult females displaying the highest bone $\delta^{44 / 42} \mathrm{Ca}$ 362 values. Finally, the correlation between adult male body mass and bone $\delta^{44 / 42} \mathrm{Ca}$ values is 363 virtually absent $(\mathrm{R}=-0.29, \mathrm{p}$-value $=0.49, \mathrm{n}=8)$. We can make no distinction between bone $364 \delta^{44 / 42} \mathrm{Ca}$ values of adult males and subadult males (Wilcoxon rank-sum test, $\mathrm{p}$-value $=0.18$ ) or 365 between adult males and subadult or yeld females (Wilcoxon rank-sum test, $p$-value $=0.62$ ).

$\left.367 \mathrm{n}^{*}=3\right)$, whereas the bone of the antler displays $\delta^{44 / 42}$ Ca values of $-1.43 \pm 0.02 \%$ ( 2 s.d., $\mathrm{n}^{*}=$ 368 4) at the base, $-1.49 \pm 0.06 \%$ o $(2$ s.d., $n *=3)$ in the middle and $-1.38 \pm 0.06 \%$ ( 2 s.d., $n *=4)$ 369 at the top of the right antler (figure 4). Each of the antler $\delta^{44 / 42} \mathrm{Ca}$ values is significantly higher 370 from that of the mandible by $0.13 \%$ or more. Calcium and phosphorus concentrations 371 decrease from the base to the tip of the antlers, whereas magnesium reaches its maximum concentration in the middle part of the antler (table S4). 


\subsection{Enamel micro-samples}

Enamel and bone $\mathrm{Ca}$ isotope data of specimen $\mathrm{AB}$ (adult male) and JVB (juvenile female) are reported in figure 5. Among these individuals, a majority of enamel $\delta^{44 / 42} \mathrm{Ca}$ values of most adult parts of M3 and M2 teeth are undistinguishable from bone, whereas the DP4 (when present) and the early mineralizing part (next to the crown apex) of the M1 display $\delta^{44 / 42} \mathrm{Ca}$ values which are $-0.23 \%$ to $-0.37 \%$ lower than bones. A similar difference is observed within the $\mathrm{M} 1$ of the $\mathrm{AB}$ specimen, with early mineralizing parts exhibiting a $\delta^{44 / 42} \mathrm{Ca}$ value $-0.22 \%$ lower than late mineralizing parts. Plant remains found between tooth cusps from $\mathrm{AB}$ and JVB display a Ca concentration of $1.83 \mathrm{wt} \%$ and $0.99 \mathrm{wt} \%$, respectively. The complete $\delta^{4 / 42} \mathrm{Ca}$ dataset of the specimens from the Bauges NRP is reported in table $\mathrm{S} 1$.

Enamel $\delta^{44 / 42} \mathrm{Ca}$ values of fossil reindeer (figure 6) range between $-1.21 \pm 0.04 \%$ (2 s.d., $\left.\mathrm{n}^{*}=3\right)$ and $-2.03 \pm 0.08 \%$ ( 2 s.d., $\left.\mathrm{n}^{*}=2\right)$. As for studied red deer, specimens with unworn M1 (JVJ and ISO M1) exhibit an important change of $\delta^{44 / 42} \mathrm{Ca}$ values between early and late mineralizing enamel. The earliest mineralizing part of the M1 display a $\delta^{44 / 42} \mathrm{Ca}$ value lower by $-0.82 \%$ for JVJ and by $-0.47 \%$ for ISO M1 compared to last mineralizing part of the M1. The enamel of the DP4 of JVJ display a $\delta^{44 / 42} \mathrm{Ca}$ value of $-1.94 \pm 0.06 \%$ o $(2$ s.d., $\mathrm{n}=$ 3), undistinguishable from that of the earliest mineralizing part of its M1 $(-2.03 \pm 0.08 \%$, 2 s.d., $\mathrm{n}^{*}=2$ ). Fluctuations of $\delta^{44 / 42} \mathrm{Ca}$ values during the adult life of reindeer are also observed within the M3 and the P4 of the AJ specimen. The mean $\delta^{44 / 42} \mathrm{Ca}$ value measured on these two teeth is $-1.56 \pm 0.19 \%$ ( 2 s.d., $\mathrm{n}=3$ for each tooth) with a total range of $0.22 \%$. The complete $\delta^{44 / 42} \mathrm{Ca}$ dataset of the specimens from Jaurens is reported in table S2.

All three DP4 teeth display a pattern of low $\delta^{44 / 42} \mathrm{Ca}$ values, relatively stable from the apex to the neck $\left(\Delta_{\max -\min }=0.11 \%\right.$; intra-teeth 2 s.d. $\left.=0.11 \%, \mathrm{n}=7\right)$. The M1 teeth display a different pattern, with $\mathrm{AB}, \mathrm{JVJ}$ and ISO M1 specimens exhibiting a high amplitude change 
397 from low to high $\delta^{44 / 42} \mathrm{Ca}$ values from the apex to the neck $\left(\Delta_{\max -m i n}=0.50 \%\right.$; intra-teeth 2 s.d. $398=0.35 \%, \mathrm{n}=3)$. The M1 of JVB displays more stable low $\delta^{44 / 42} \mathrm{Ca}$ values $\left(\Delta_{\max -\min }=0.17 \%\right.$; 399 intra-teeth 2 s.d. $=0.12 \%, \mathrm{n}=7$ ), whereas the M1 of AJ displays stable $\delta^{44 / 42} \mathrm{Ca}$ values close 400 to its M2 and M3 $\delta^{44 / 42} \mathrm{Ca}$ values $\left(\Delta_{\max -\min }=0.11 \%\right.$; intra-teeth 2 s.d. $\left.=0.12 \%, \mathrm{n}=3\right)$.

401

419 mineralization periods). 
420

421

423

424

425

426

427

428

429

431

432

433

434

\subsection{Physiological control on $\delta^{44 / 42}$ Ca values in adult tissues}

\subsubsection{Gestation effects}

In the red deer population from Bauges NRP, adult females who recently gave birth (referred as lactating hinds) display a mean bone $\delta^{44 / 42} \mathrm{Ca}$ value of $+0.17 \pm 0.10 \%$ (95\% confidence interval) higher than adult males (figure 3). This is similar to what was previously reported for domestic sheep (Reynard et al., 2010), in which females $(n=8)$ displayed a bone $\delta^{44 / 42} \mathrm{Ca}$ value significantly higher of $+0.14 \pm 0.08 \%$ (95\% confidence interval) compared to males $(n=16)$. The two factors pointed to be the cause of this sexual driven difference in sheep were the accretion of bone during gestation and the excretion of milk (Reynard et al., 2010), as only these two Ca fluxes were thought to be associated with $\mathrm{Ca}$ isotope fractionation at this time. However, the very low enamel $\delta^{44 / 42} \mathrm{Ca}$ values we record in cervid teeth mineralizing in utero (DP4, early M1, figure 5 and 6) suggest that during gestation a mother will preferentially transfer light $\mathrm{Ca}$ isotopes through placental $\mathrm{Ca}$ transfer. This is also observed in human deciduous teeth (Tacail et al., 2017, 2019), although recent data point out that it could be representative of the last stage of gestation only (Li et al., 2020). Such trapping of isotopically light $\mathrm{Ca}$ by the foetus would have comparatively enriched mother tissues in heavy $\mathrm{Ca}$ isotopes (including mineralizing bone or enamel). The most simplistic box model of gestation (a 2 box model with a $\Delta^{44 / 42} \mathrm{Ca}_{\text {fawn-hind }}$ of $-0.25 \%$ and a hind giving $10 \%$ of her $\mathrm{Ca}$ to her fawn) gives a $\delta^{44 / 42} \mathrm{Ca}$ shift of +0.02 to $+0.03 \%$ for the hind, but it has to be noted that this model is very simplistic and amplifies the shift compared to reality (notably by neglecting $\mathrm{Ca}$ transfers from the foetus to the hind and the $\mathrm{Ca}$ intake of the hind). Among other changes, gestation also triggers higher Ca urinary excretions (Giesemann et al., 1998; Kovacs and Fuleihan, 2006; Reynard et al., 2010), a Ca flux which contributes to lower blood $\delta^{44 / 42} \mathrm{Ca}$ values by preferentially exporting heavy $\mathrm{Ca}$ isotopes in urines (Skulan et al., 2007; 
444 Heuser and Eisenhauer, 2010; Morgan et al., 2012; Tacail et al., 2014; Channon et al., 2015; 445 Heuser et al., 2016, 2019; Tacail, 2017; Eisenhauer et al., 2019). Thus, the consequences of 446 gestation have opposite influences on blood $\mathrm{Ca}$ isotope composition, and therefore limit the

447 record of a gestation signal in bone and enamel. Moreover, the recent questioning about the $448 \alpha_{\text {blood-bone }}$ amplitude (Tacail, 2017; Tacail et al., 2020) also questions the base of the bone 449 accretion effect. Further investigations are necessary on this topic but at the moment these 450 sparse data tend to demonstrate that gestation has a weak to absent effect on body Ca isotope

464 females in Ca heavy isotopes (Reynard et al., 2010). Along with important Ca excretion 465 through milk, lactating mammals are subject to higher absorption in the digestive tract, to 466 bone loss and to changes in Ca urinary excretion (Ramberg Jr et al., 1970; Cross et al., 1995; 467 Giesemann et al., 1998; Karlsson et al., 2001; Wysolmerski, 2002; Vanhouten and 20 
468 Wysolmerski, 2003; Kovacs and Fuleihan, 2006; Tacail, 2017). However, such Ca flux changes likely secondarily affect the lactation signal, as these changes stay minimal compared to the order of magnitude of milk excretion. The lactation should therefore be characterized by higher body $\delta^{44 / 42} \mathrm{Ca}$ values in hinds, including within their bones if the nursing lasts for several months (see appendix). In this context, the high bone $\delta^{44 / 42} \mathrm{Ca}$ values reported in lactating hinds (figure 2 and 3) seems very compatible with the manifestation of a lactation effect, similarly to what is observed for domestic sheep (Reynard et al., 2010). The important residence time of $\mathrm{Ca}$ in bones certainly heavily damps this lactation signal (see appendix), although the extensive bone remodeling and bone losses usually recorded during lactation decreases this residence time and improves the potential of the signal to be recorded (Giesemann et al., 1998; Vanhouten and Wysolmerski, 2003; Kovacs and Fuleihan, 2006). Looking at subadult hinds for such a signal is more difficult, as their reproductive status is challenging to assess and that only about $50 \%$ gave birth to fawns at two years according to OFB monitoring in Bauges NRP. However, higher body mass also suggests higher chance that they gave birth to a fawn during the last birth season (Mitchell et al., 1976; Clutton-Brock et al., 1982; Albon et al., 1986; Pellerin et al., 2014). Thus, the fact that bone $\delta^{44 / 42} \mathrm{Ca}$ values of subadult females overlap with both lactating and yeld adult hinds suggest that this group includes both nulliparous and primiparous females (figure 3). This is also consistent with the fact that the heaviest subadult female displays the highest $\delta^{44 / 42} \mathrm{Ca}$ values, suggesting that this specimen gave birth to a fawn during the last birth season.

Interestingly, the female with the highest body mass of our dataset displays lower bone $\delta^{44 / 42} \mathrm{Ca}$ values despite having an age and body mass suggesting lactating periods in previous birth seasons, as high body mass mean higher reproduction chances (Albon et al., 1986; Pellerin et al., 2014). This suggests that skeletal Ca turnover is intense enough to conceal 
492 lactation signals from one year to another in this species, at least within the cortical part of the dentary bone (the bone part analyzed in this study). We lack precise data about bone remodeling rate for red deer dentary bone. However, this fast $\mathrm{Ca}$ turnover seems odd considering that the total skeleton would need about 9 years to remove $75 \%$ of a lactation signal (see box model described in appendix). The post-lactation bone accretion and the 497 relatively small male/female $\delta^{44 / 42} \mathrm{Ca}$ difference observed so far might help to achieve a 498 quicker concealing of the lactation signal, but further experiments are necessary to confirm this dynamic as only one individual suggests this tendency. If bone Ca isotope composition proves to be that dynamic, the time interval between last lactation and death, as well as the

501 time interval between consecutive lactations might be critical to preserve a lactation signal 502 within bone $\mathrm{Ca}$ isotope composition. Nevertheless, the amount of produced milk, the duration 503 of lactation periods and the size of the skeleton Ca reservoir also likely modulate this sex 504 driven $\mathrm{Ca}$ isotopic difference among mammal species. Those factors are probably a key to explain why human populations studied by Reynard et al. (2010, 2013) display non506 significant isotopic clustering between sexes, along with the diversity of possible food sources 507 which characterize humans. Such lactation signal is in theory less dampened in enamel than in 508 bones (see appendix). However, looking for these signals in adult teeth of red deer females 509 seems challenging, as the enamel of the last tooth to mineralize (i.e. the M3) has generally completed its mineralization around 26 months (Brown and Chapman, 1991b), while only

511 about half of two-year-old females are primiparous. We cannot be certain of that concerning 512 the reindeer population of Jaurens. However, our data suggest that any record of a lactation 513 signal within their enamel would result in higher enamel $\delta^{44 / 42} \mathrm{Ca}$ values, whereas these 514 reindeers exhibit suspiciously low $\delta^{44 / 42} \mathrm{Ca}$ values. We thus conclude that lactation effects on 
515 body $\mathrm{Ca}$ isotope composition have to be considered when studying mammal populations but

516 cannot be invoked to explain anomalously low bone or enamel $\delta^{44 / 42} \mathrm{Ca}$ values.

\subsubsection{Antlerogenesis effects and antler records}

We report the first comparison between $\mathrm{Ca}$ isotope compositions of antlers and the rest of the skeleton (figure 4). This pilot investigation highlights that antlers display $\delta^{44 / 42} \mathrm{Ca}$ values significantly higher than the rest of the skeleton. As for enamel and bones, the key is to assess whether this difference is the result from differences in $\mathrm{Ca}$ isotope fractionation coefficients at mineralization or the result of a different mineralization timing. These data call for further studies, as comparing antlers with bone and enamel could add an additional dimension for studying cervid life history traits using $\mathrm{Ca}$ isotopes, allowing to further investigate diet seasonality, for example.

With the only data presented in figure 4, it seems that antlers could preferentially trap heavy $\mathrm{Ca}$ isotopes from blood, although physiological processes generally favor light $\mathrm{Ca}$ isotopes (Tacail, 2017). If further confirmed, this would indicate that antlerogenesis could lower body $\mathrm{Ca}$ isotope composition. Indeed, antlers act primarily as a $\mathrm{Ca}$ sink working similarly as lactation and gestation by isolating $\mathrm{Ca}$ from the rest of the body, although antlers are also subject to bone remodeling (Bélanger et al., 1967; Muir et al., 1987a; Rolf and Enderle, 1999). However, the fact that lactation proved to have a relatively tenuous influence on bone $\delta^{44 / 42} \mathrm{Ca}$ values, despite involving far bigger $\mathrm{Ca}$ fluxes and $\mathrm{Ca}$ isotope fractionation coefficients than antlerogenesis (Mitchell et al., 1976; Muir et al., 1987a, 1987b; Harris et al., 2002; Thomas and Barry, 2005; Li, 2013), suggests that antlerogenesis will not be detectable within the skeleton $\mathrm{Ca}$ isotope composition. This is supported by the complete overlap we observe between male red deer, yeld and immature hinds bone $\delta^{44 / 42} \mathrm{Ca}$ values (figure 3). An overlap which occurs despite the fact that studied specimens have been slaughtered just when 
539 the antlers of males finished their growth (Mitchell et al., 1976), so just when antlerogenesis

540 could had a strong influence on skeleton $\mathrm{Ca}$ isotope composition. Although further tests are

541 necessary to prove that enamel stay unaffected too, the end of enamel mineralization occurs

542 before large antlers can grow (Kruuk et al., 2002; Thomas and Barry, 2005) which suggests

543 that enamel will stay largely unaffected by antlerogenesis. In conclusion, none of our data

544 suggests that antlerogenesis could be an important driver of body Ca isotope compositions

545 and result in significant mismatch of $\mathrm{Ca}$ isotope compositions and trophic data.

546

547

548

549

551

552

553

554

555

556

557

558

559

560

561

562

\subsection{Nutrition control over bone and enamel $\delta^{44 / 42}$ Ca values in modern and fossil cervids}

\subsubsection{Neonatal life history traits}

We discussed how gestation, lactation and antlerogenesis could affect adult bone and enamel $\delta^{44 / 42} \mathrm{Ca}$ values, and neither of these phenomena can convincingly explain the low $\delta^{44 / 42} \mathrm{Ca}$ values found in reindeer populations (Martin et al., 2017a). However, gestation and lactation not only affect adult $\mathrm{Ca}$ isotope composition, they also control juvenile $\mathrm{Ca}$ intakes and the Ca isotope composition of their tissues. For the 5 studied cervids with a preserved DP4 or unworn M1 (AB, JVB, JVJ, ISO M1, ISO DP4), enamel mineralizing in utero systematically exhibits the lowest $\delta^{44 / 42} \mathrm{Ca}$ values recorded (figure 5, 6). DP4 teeth exhibit stable and low $\delta^{44 / 42} \mathrm{Ca}$ values relatively to third molars (M3) and adult bones, whereas M1 teeth exhibit various rates of transition from early ontogenetic low $\delta^{44 / 42} \mathrm{Ca}$ values to late ontogenetic high $\delta^{44 / 42} \mathrm{Ca}$ values. A similar pattern of $\mathrm{Ca}$ isotope composition has been previously described in human deciduous teeth, in which a clear link between weaning practices and $\delta^{4 / 42} \mathrm{Ca}$ values has been described (Tacail et al., 2017). We thus propose that the transition from low $\delta^{44 / 42} \mathrm{Ca}$ values in DP4 and in the apex of M1, to high $\delta^{44 / 42} \mathrm{Ca}$ values in the neck of the M1, in the M2, M3 and adult bones is characteristic of the transition from maternal $\mathrm{Ca}$ transfer (during the gestation then the nursing) to post-weaning $\mathrm{Ca}$ intake (adult- 
563 like diet). The mineralization timing and enamel $\delta^{44 / 42} \mathrm{Ca}$ values of red deer and reindeer are 564 consistent with the 3-8 months of weaning age of these species (Miller, 1972; Mitchell et al., 565 1976; Brown and Chapman, 1991b; Jones et al., 2009). The specimens AB, JVB and ISO M1

566 all reached adult $\mathrm{Ca}$ isotope composition at the neck of the M1. This suggests that they were 567 weaned before four months considering the length of enamel mineralization (figure 5, 6 and 568 appendix). Data from AJ (figure 6) also suggest a relatively early weaning, although the wear 569 of the M1 limits the record of pre-weaning conditions. The JVB specimen constitutes an exception to this early transition of $\delta^{44 / 42} \mathrm{Ca}$ values in the M1. For this individual, the increase

571 of $\delta^{44 / 42} \mathrm{Ca}$ values within the M1 seems flattened (see figure 5; $\Delta_{\max \text {-min }}=0.17 \%$; intra-tooth 2 572 s.d. $=0.12 \%, \mathrm{n}=7$ ), and enamel $\delta^{44 / 42} \mathrm{Ca}$ values only approach bone-like values within the 573 M2 and M3 late mineralizing sections. This suggests a later weaning for this individual 574 (around 8 months), or alternatively an earlier tooth mineralization. The fact that these weaning 575 ages seem consistent with the observations of these species in the wild, supports that $\mathrm{Ca}$ 576 isotopes are accurate for detecting in utero, milk feeding and weaning periods among 577 mammals. These data also highlight that some individuals (like JVB) could display late 578 dietary transition to purely adult diet (i.e. without milk), in a way that the transition is not yet 579 complete when M2 teeth mineralize. This supports that milk consumption could have affected 580 the previously published data of cervids from Jaurens (Martin et al., 2017a) and caused their 581 suspiciously low enamel $\delta^{44 / 42} \mathrm{Ca}$ values. For these cervid species, we consequently advise to 582 favor M3 enamel sampling to infer purely adult trophic information (when accessible). Note 583 that in $\mathrm{M} 3$, enamel can then display higher $\delta^{44 / 42} \mathrm{Ca}$ values in case of an early breeding and 584 subsequent lactation (see 4.2.2 section). When possible, we thus advise to analyze enamel 585 zones which mineralized after weaning and prior to female sexual maturity. As the position of 586 these zones are difficult to predict, especially for fossil species, we advise to use serial micro- 
587 588

589 quantified. However, we know from a red deer population from Spain that about two hundred

sampling in order to identify early post-weaning periods. This approach provides useful complementary information for ecological and physiological inferences and minimizes the potential of lactating females and nursing to affect trophic inferences based on $\delta^{44 / 42} \mathrm{Ca}$ data.

\subsubsection{Osteophagia and mineral licks}

Osteophagia (i.e. bone consumption) and the consumption of natural mineral licks are two common sources of mineral supplementation that cervids, and more generally artiodactyls, use during periods of high mineral requirement (e.g. lactation, juvenile growth, antlerogenesis), notably to cope with phosphorus (P) or other element deficiency (Cowan and Brink, 1949; Kjos-Hanssen, 1973; Krausman and Bissonette, 1977; Marie, 1982; Grasman and Hellgren, 1993; Cáceres et al., 2011; Gambín et al., 2017). There is yet no direct measure of mineral supplementation effects on enamel $\mathrm{Ca}$ isotope composition in the literature. However, we can confidently assume that, because bones are generally ${ }^{44} \mathrm{Ca}$-depleted compared to plant products (Gussone and Heuser, 2016), antler or other bone consumption will result in lower dietary $\delta^{44 / 42} \mathrm{Ca}$ values (Gussone and Heuser, 2016; Martin et al., 2017a, 2018). We can roughly estimate that this change of dietary $\delta^{44 / 42} \mathrm{Ca}$ value will be of 0 to $-2 \%$, depending of the amount of consumed bones and their Ca isotope compositions (Heuser et al., 2011; Gussone and Heuser, 2016). Foraging on mineral licks would have the opposite effect on dietary $\delta^{44 / 42} \mathrm{Ca}$ value (about 0 to $+1 \%$ ), because soils and rocks are generally ${ }^{44} \mathrm{Ca}$ enriched compared to plant products (Gussone and Heuser, 2016). These modifications of the dietary Ca isotope composition logically affect the $\delta^{44 / 42} \mathrm{Ca}$ values of growing enamel, with an intensity that will depend upon the rate of enamel growth and the duration of the mineral supplementation.

The resort to mineral supplementation by red deer from Bauges NRP has not been 
611 individuals can consume about $966 \mathrm{~g}$ of antlers over 7 months, mainly during lactation,

612 weaning and antlerogenesis periods (Estevez et al., 2008; Gambín et al., 2017). If we consider

613 that antlers contained a maximum of $15 \%$ of $\mathrm{Ca}$ (see appendix), this would represent about

$6140.7 \mathrm{~g}$ of $\mathrm{Ca}$ intake per individual. Considering that mineral supplementations were enhanced

615 by the low P availability in the plants of the study site in Spain (Estévez et al., 2009; Gambín

616 et al., 2017), we can expect a lower to similar intensity of mineral supplementations within

617 the Bauges NRP red deer population. Such Ca intakes seem negligible over a year compared 618 to plant and water sources, which suggests that mineral supplementations likely have a 619 negligible influence on bone $\delta^{44 / 42} \mathrm{Ca}$ values. However, few individuals may have been 620 responsible for most of this bone consumption (individuals were not identified in Gambín et 621 al. (2017)), and cervids from this study likely had access to other bones and mineral sources 622 than monitored antler stacks (Gambín et al., 2017). Therefore, it seems plausible to expect at 623 least short excursions in enamel $\delta^{44 / 42} \mathrm{Ca}$ values (negative for osteophagia, positive for mineral 624 licking) for individuals experiencing periods of important supplementation (i.e. lactation, 625 weaning, antlerogenesis). Following this postulate, we suspect that the outlier $\delta^{44 / 42} \mathrm{Ca}$ value 626 in the M3 of the JVB specimen has been influenced by osteophagia. This data point is 627 characterized by an isolated low $\delta^{44 / 42} \mathrm{Ca}$ value, localized far after weaning in enamel formed 628 around 15 months of age (figure 5), a period which could match the peak of supplementation 629 reported in September by Gambín et al. (2017). Finally, we note that the two latest M2 $630 \delta^{44 / 42} \mathrm{Ca}$ values of $\mathrm{AB}$ (at 10 months) seem slightly higher than the average M2, M3 and bone $631 \delta^{44 / 42} \mathrm{Ca}$ values of this specimen (figure 5). It is possible that this results from Ca intakes 632 influenced by mineral licking, but the isotopic difference is tenuous, possibly artefactual, and 633 does not match with the common periods of mineral supplementation recorded in Spain 634 (Gambín et al., 2017). 
Reindeer are also known to seasonally resort to mineral supplementation, likely to

636 compensate for the low $\mathrm{P}, \mathrm{Ca}$ and sodium content of the plants and lichens they consume

637 (Grasman and Hellgren, 1993). Frequent antler chewing are reported in spring during the

638 calving season (Kjos-Hanssen, 1973; Marie, 1982), as well as mineral licks, notably in the

639 summer (Cowan and Brink, 1949). We have no data to quantify these supplementations, but it

640 seems reasonable to suspect they can influence enamel $\delta^{44 / 42} \mathrm{Ca}$ values. A possible example is

641 found within the M1 tooth of the JVJ specimen at 5 months (figure 6). This enamel zone

642 constitutes the terminal part of the weaning transition, and is characterized by a higher $\delta^{44 / 42} \mathrm{Ca}$

643 value than within the M2 of the specimen (or of any other enamel sample from Jaurens

644 specimens). Because this critical period favors mineral supplementations in cervids (see

645 previous paragraph), we suspect that this positive $\delta^{44 / 42} \mathrm{Ca}$ excursion is the result of mineral

646 licking, although the very limited post-weaning JVJ dataset provides limited evidence for this.

If the effects of mineral supplementation on body $\mathrm{Ca}$ isotope composition are further

648 confirmed, this proxy could be used to study this crucial survival behavior among modern and

649 fossil mammals. As such, mineral supplementations however complicate the relation between

650 trophic level and enamel $\mathrm{Ca}$ isotope composition. Thus, we emphasize the importance of 651 considering mineral supplementation behaviors when using $\delta^{44 / 42} \mathrm{Ca}$ data for trophic

652 interpretations. We notably suggest a specific attention toward this behavior for the study of 653 artiodactyls from arid or tropical environments, because these environments are generally 654 marked by a low P availability in plants, a trigger for mineral supplementations (Grasman and 655 Hellgren, 1993).

\subsubsection{Plant Ca isotopic variability}

Identifying and excluding enamel $\delta^{44 / 42} \mathrm{Ca}$ data affected by pre-weaning, lactation and short term mineral supplementation periods allow, with some limits (see previous section), to 
659 identify $\mathrm{Ca}$ isotope data that are representative of trophic level. However, the important 660 variability of plant $\mathrm{Ca}$ isotope compositions can also limit the trophic clustering of enamel 661 and bone $\delta^{44 / 42} \mathrm{Ca}$ data, by generating isotopic variability among herbivores (Martin et al., 662 2018). Plant Ca isotope compositions combine a variability between plant organs and between 663 plant taxa (Holmden and Bélanger, 2010; Gussone and Heuser, 2016; Schmitt, 2016; Moynier 664 and Fujii, 2017; Martin et al., 2018; Griffith et al., 2020). The mean offset of $-0.31 \pm 0.14 \%$ 665 observed between the leaves of dicotyledons and monocotyledons (e.g. grasses) is notably 666 suspected to cause the documented difference of $-0.18 \pm 0.10 \%$ between the enamel of 667 browser herbivores (i.e. with a leaf-dominated diet) and of grazer herbivores (i.e. with a grass668 dominated diet) (Martin et al., 2018). Red deer is described as a mixed feeder, changing 669 seasonally or regionally between more browser to more grazer diets (Hearney and Jennings, 670 1983; Gebert and Verheyden-Tixier, 2001; Storms et al., 2008; Berlioz et al., 2019). In the 671 Bauges NRP, the grass proportion in the red deer diet has been estimated to change between $67220 \%$ and $40 \%$ from summer to winter (Redjadj et al., 2014), and could be lower during late 673 winter, spring and early summer according to the tendencies observed at the limits of 674 monitored periods (Redjadj et al., 2014). Changing diet proportions from $40 \%$ grass and 60 $675 \%$ leaves to $10 \%$ grass and $90 \%$ leaves would change the diet $\delta^{44 / 42} \mathrm{Ca}$ value of about $0.09 \%$, 676 a result which is relatively close to the post-weaning range of $0.11 \%$ observed in the enamel 677 record of the $\mathrm{AB}$ specimen (the red deer specimen with the most extensive post-weaning 678 enamel record, figure 5). Our isotopic data are thus compatible, at the first order, with the 679 known diet variability of this cervid population, although this estimation of $0.09 \%$ is built 680 upon coarse approximations (notably that consumed grass $\delta^{44 / 42} \mathrm{Ca}$ value was exactly $-0.31 \%$ 681 lower than non-grass food $\delta^{44 / 42} \mathrm{Ca}$ value) and need further investigations. A higher resolution 682 regarding the post-weaning enamel record, and a better constrain of the $\mathrm{Ca}$ isotope 
683

684

685

686

687

688

689

690

691

692

693

694

695

696

697

698

699

700

701

702

703

704

705

composition of food items available at Bauges NRP (especially evergreen trees which are an important food source for these red deer, Redjadj et al. (2014)) would provide $\delta^{44 / 42} \mathrm{Ca}$ data that will be more comparable with $\delta^{13} \mathrm{C}$ records, dental micro-wear and stomach content data collected so far for this red deer population (Redjadj et al., 2014; Merceron et al., 2021). Such further studies could notably help resolving some discrepancies between dental micro-wear and stomach content estimations (i.e. higher versus lower grass content in the diet, Merceron et al. (2021)), and provide independent complementary information regarding $\delta^{13} \mathrm{C}$ data (e.g. diet and ecological niche).

Reindeers are also mixed-feeders, but consume lichen during winter and have a generally more browser diet compared to red deer (Hofmann, 1989; Mathiesen et al., 2000), an observation which is notably consistent with the higher $\delta^{44 / 42} \mathrm{Ca}$ values of reindeers compared to red deers when both co-exist within the same fauna (Dodat et al., 2021). After weaning, the AJ specimen (the reindeer with the most extensive post-weaning enamel record) exhibits a $\delta^{44 / 42} \mathrm{Ca}$ range of $0.25 \%$ (figure 6). As for red deer, this isotopic variability is compatible, at the first order, with the consequences expected from changing proportions of grass and other plant items in the diet. Within this browser to grazer-like diet continuum, the lowest enamel $\delta^{44 / 42} \mathrm{Ca}$ values would correspond to more grazer-like diet periods, whereas periods with the highest enamel $\delta^{44 / 42} \mathrm{Ca}$ values would correspond to more browser-like diet periods. A limit to this hypothesis is the potential occurrence of mineral supplementations which can modify the dietary Ca isotope composition independently of the plants (see section 4.3.3). In this regard, combining $\delta^{44 / 42} \mathrm{Ca}$ data and $\delta^{13} \mathrm{C}$ data within a multi-proxy approach (e.g. Martin et al., 2018) would be a solid option to further investigate diet and mineral supplementation seasonality among these cervids. 


\subsubsection{Trophic position of Pleistocene fossil cervids}

The previous discussion sections detail how to identify tooth and enamel parts that should be favored for trophic inter-specific comparisons (by identifying pre- and postweaning periods, by detecting sections potentially disrupted by short term mineral supplementation, and by providing insight about intra-tooth $\delta^{44 / 42} \mathrm{Ca}$ variability). We applied this technic to three subadult to adult reindeers (AJ, JVJ, ISO M1) from the Late Pleistocene locality of Jaurens. The most suited enamel data points for trophic inter-specific comparisons are indicated in figure 6. Unfortunately, we do not have access to an extensive M2 and M3 dataset for JVJ and ISO M1 specimens (figure 6). Therefore, we lake insight to determine if the enamel data points we selected for trophic inter-specific comparisons are entirely posterior to the weaning transition. Nevertheless, the selected data points of these specimens consistently range within the enamel Ca isotope compositions of $\mathrm{AJ}$, which supports that they are representative of a post-weaning diet. Altogether, the weighted average (per specimen) of selected enamel $\delta^{44 / 42} \mathrm{Ca}$ values is $+0.18 \%$ higher than previously published measures (Martin et al., 2017a). They consequently plot within the range of woolly rhinoceroses (Coelodonta antiquitatis, $\mathrm{n}=3$ ) (Wilcoxon rank-sum test, $\mathrm{p}$-value $=0.1$ ) and steppe bisons (Bison priscus, $\mathrm{n}=3$; Wilcoxon rank-sum test, $\mathrm{p}$-value $=0.2$ ) published by Martin et al. (2017a). This demonstrates that dismissing the data obtained from enamel affected by short term mineral supplementation or milk consumption, based on a serial micro-sampling approach, efficiently resolve the anomaly of ${ }^{44} \mathrm{Ca}$ depletion previously reported in the enamel of reindeers from Jaurens. Serial micro-sampling is time and resource consuming and thus can hardly be used at the scale of a whole faunal assemblage, but this study proves that this technique is particularly suited to discuss of diet and behavior at the individual scale, or when some $\delta^{44 / 42} \mathrm{Ca}$ data are at odds with independently inferred trophic positions or diet. 
730

731

732

733

734

735

736

737

738

739

740

741

742

743

744

745

746

747

748

750

751

752

753

\section{Conclusions}

In this paper we discussed the behavioral and physiological events likely to affect mammalian enamel and bone Ca isotope compositions, with two species of cervids as models (Cervus elaphus, Rangifer tarandus). Our results highlight that lactation is an effective source of $\mathrm{Ca}$ isotope variability as this phenomenon produced ${ }^{44} \mathrm{Ca}$-enriched isotope composition in bones of lactating females. Our study, however, failed to show any comparable gestation effect, likely because of long $\mathrm{Ca}$ residence time in cervid bones, and lower $\mathrm{Ca}$ fluxes or $\mathrm{Ca}$ isotope fractionation coefficients involved in cervid gestation. Similarly, antlerogenesis did not prove to be a significant driver of body $\mathrm{Ca}$ isotope composition in red deer. However, our data highlight that antlers display a different $\mathrm{Ca}$ isotopic signature than the rest of the skeleton, encouraging further studies. The $\mathrm{Ca}$ transferred from the cervid mother to the foetus during gestation has a similar isotope composition than milk according to data from enamel mineralizing in utero, at least close before birth. The transition from pre-parturition and pre-weaning $\mathrm{Ca}$ intakes to adult diet is clearly observed within the enamel of most of the studied individuals. Calcium isotopes can then be efficiently used for assessing weaning ages, providing the fact that no osteophagia is involved early in life, as this phenomenon is also able to generate low bone and enamel $\delta^{44 / 42} \mathrm{Ca}$ values (at the opposite of what is expected from mineral licks foraging). Finally, this study demonstrates that serial micro-sampling of enamel is an appropriate method to disentangle part of ecological, physiological and environmental $\mathrm{Ca}$ isotope signals. This method allowed to accurately extract trophic information from the enamel $\delta^{44 / 42} \mathrm{Ca}$ values of the reindeers from the Pleistocene deposit of Jaurens. When possible, we thus encourage the use of this method in order to accurately retrieve diet and trophic signals from enamel $\delta^{44 / 42} \mathrm{Ca}$ data. Such an approach would greatly benefit to paleoecology fields, as it makes Ca isotope 
754 data more readily comparable with other diet proxy such as carbon and nitrogen isotopes.

755 Further studies are needed to investigate other cases of discrepancy between $\delta^{44 / 42} \mathrm{Ca}$ data and 756 trophic level, as well as to assess the variability of lactation, gestation and mineral

757 supplementation signals among mammals. However, these results open great perspectives for 758 the study of mammal physiology in addition to clarify the trophic inferences achievable with 759 Ca isotopes.

\section{Acknowledgements}

This research was supported by the TelluS program of CNRS/INSU (DIUNIS project to JEM) and ENS de Lyon. We thank D. Mollex for his help regarding thin section preparation, D. Berthet for allowing access to the specimen curated in the collections of the Musée des Confluences, Lyon, and E. Robert for allowing access to Jaurens specimens curated in the paleontological collections of the LGL-TPE. We would like to thank the OGFH, the Groupement d'Intérêt Cynégétique des Bauges, the Office National des Forêts, as well as the hunters and professionals from the ONCFS (T. Chevrier and T. Amblard) who contributed to collect red deer data in Bauges NRP. Finally we thank the two reviewers, XXX and XXX as well as the editor T. Tütken for their detailed comments that improved the initial version of this work.

\section{References}

Albon, S.D., Mitchell, B., Huby, B.J., Brown, D., 1986. Fertility in female Red deer (Cervus elaphus): the effects of body composition, age and reproductive status. J. Zool. 209, $447-460$.

Azorit, C., Analla, M., Carrasco, R., Calvo, J.A., Muñoz-Cobo, J., 2002. Teeth eruption pattern in red deer (Cervus elaphus hispanicus) in southern Spain. An. Biol. 24, 107- 
114.

778

779

780

781

782

783

Bélanger, L.F., Choquette, L.P.E., Cousineau, J.G., 1967. Osteolysis in reindeer antlers; Sexual and seasonal variations. Calcif. Tissue Res. 1, 37-43. https://doi.org/10.1007/BF02008073

Berlioz, E., Azorit, C., Blondel, C., Ruiz, M.S.T., Merceron, G., 2019. Deer in an arid habitat: dental microwear textures track feeding adaptability. Hystrix, Ital. J. Mammal. 28, 222230. https://doi.org/10.4404/hystrix

Biewener, A.A., 1990. Biomechanics of mammalian terrestrial locomotion. Science 250, 1097-1103. https://doi.org/10.1126/science.2251499

Blaine, J., Chonchol, M., Levi, M., 2015. Renal control of calcium, phosphate, and magnesium homeostasis. Clin. J. Am. Soc. Nephrol. 10, 1257-1272. https://doi.org/10.2215/CJN.09750913

Blumenthal, S.A., Cerling, T.E., Chritz, K.L., Bromage, T.G., Kozdon, R., Valley, J.W., 2014. Stable isotope time-series in mammalian teeth: In situ $\delta^{18} \mathrm{O}$ from the innermost enamel layer. Geochim. Cosmochim. Acta 124, 223-236. https://doi.org/10.1016/j.gca.2013.09.032

Brown, W.A.B., Chapman, N.G., 1991a. The dentition of red deer (Cervus elaphus): a scoring scheme to assess age from wear of the permanent molariform teeth. J. Zool. London 224, $519-536$.

Brown, W.A.B., Chapman, N.G., 1991b. Age assessment of red deer (Cervus elaphus): from a scoring scheme based on radiographs of developing permanent molariform teeth. $\mathrm{J}$. Zool. London 225, 85-97. https://doi.org/10.1111/j.1469-7998.1991.tb03803.x 
799 800

801 802 803

804 805 806 807 808 809 810 811

Cáceres, I., Esteban-Nadal, M., Bennàsar, M., Fernández-Jalvo, Y., 2011. Was it the deer or the fox? J. Archaeol. Sci. 38, 2767-2774. https://doi.org/10.1016/j.jas.2011.06.020

Channon, M.B., Gordon, G.W., Morgan, J.L.L., Skulan, J.L., Smith, S.M., Anbar, A.D., 2015. Using natural, stable calcium isotopes of human blood to detect and monitor changes in bone mineral balance. Bone 77, 69-74. https://doi.org/10.1016/j.bone.2015.04.023

Chu, N.C., Henderson, G.M., Belshaw, N.S., Hedges, R.E.M., 2006. Establishing the potential of $\mathrm{Ca}$ isotopes as proxy for consumption of dairy products. Appl. Geochem. 21, 1656-1667. https://doi.org/10.1016/j.apgeochem.2006.07.003

Clementz, M.T., 2012. New insight from old bones: stable isotope analysis of fossil mammals. J. Mammal. 93, 368-380. https://doi.org/10.1644/11-MAMM-S-179.1

Clementz, M.T., Holden, P., Koch, P.L., 2003. Are calcium isotopes a reliable monitor of trophic level in marine settings? Int. J. Osteoarchaeol. 13, 29-36. https://doi.org/10.1002/oa.657

Clutton-Brock, T.H., Iason, G.R., Albon, S.D., Guiness, F.E., 1982. The effects of lactation on feeding behavior in wild red deer hinds. J. Zool. London 198, 227-236.

Cowan, I.M., Brink, V.C., 1949. Natural game licks in the rocky mountain national parks of Canada. Am. Soc. Mammal. 30, 379-387.

Cross, N.A., Hillman, L.S., Allen, S.H., Krause, G.F., Vieira, N.E., 1995. Calcium homeostasis and bone metabolism during pregnancy, lactation, and postweaning: a longitudinal study. Am. J. Clin. Nutr. 61, 514-523. https://doi.org/10.1093/ajcn/61.3.514

Dean, M.C., Spiers, K.M., Jan, G., Le Cabec, A., 2019. Synchrotron X-ray fluorescence mapping of $\mathrm{Ca}, \mathrm{Sr}$ and $\mathrm{Zn}$ at the neonatal line in human deciduous teeth reflects 35 
changing perinatal physiology

Arch.

Oral

Biol. https://doi.org/https://doi.org/10.1016/j.archoralbio.2019.05.024

823

Dodat, P.-J., Tacail, T., Albalat, E., Gomez-Olivencia, A., Couture-Veschambre, C., Holliday, T., Madelaine, S., Martin, J.E., Rmoutilova, R., Maureille, B., Balter, V., 2021. Isotopic calcium biogeochemistry of MIS 5 fossil vertebrate bones : application to the study of the dietary reconstruction of Regourdou 1 Neandertal fossil. J. Hum. Evol. 151, 102925. https://doi.org/10.1016/j.jhevol.2020.102925

Eisenhauer, A., Müller, M., Heuser, A., Kolevica, A., Glüer, C.C., Both, M., Laue, C., Hehn, U. V., Kloth, S., Shroff, R., Schrezenmeir, J., 2019. Calcium isotope ratios in blood and urine: A new biomarker for the diagnosis of osteoporosis. Bone Reports 10, 100200. https://doi.org/10.1016/j.bonr.2019.100200

Estévez, J.A., Ceacero, F., Martínez, A., García, A.J., Landete-Castillejos, T., Gaspar-López, E., López-Parra, J.E., Olguín-Hernández, C.A., Calatayud, A., Gallego, L., 2009. Variación estacional en la composición mineral de plantas y su aplicación a la gestión del ciervo ibérico, in: XXXIV Congreso Nacional de La Sociedad Española de Ovinotecnia y Caprinotecnia (SEOC): Barbastro. Huesca, pp. 596-601.

Estevez, J.A., Landete-Castillejos, T., García, A.J., Ceacero, F., Gallego, L., 2008. Population management and bone structural effects in composition and radio-opacity of Iberian red deer (Cervus elaphus hispanicus) antlers. Eur. J. Wildl. Res. 54, 215-223. https://doi.org/10.1007/s10344-007-0132-0

Ewbank, J.M., Phillipson, D.W., Whitehouse, R.D., Higgs, E.S., 1964. Sheep in the Iron Age: a method of study. Proc. Prehist. Soc. 30, 423-426. https://doi.org/10.1017/S0079497X0001519X 
844 Fricke, H.C., Clyde, W.C., James, R.O., 1998. Intra-tooth variations in $\delta^{18} \mathrm{O}\left(\mathrm{PO}_{4}\right)$ of 845 mammalian tooth enamel as a record of seasonal variations in continental climate variables. Geochim. Cosmochim. Acta 62, 1839-1850.

847

848

Gallego, L., Landete-Castillejos, T., Garcia, A., Sanchez, P.J., 2006. Seasonal and lactational changes in mineral composition of milk from Iberian red deer (Cervus elaphus hispanicus). J. Dairy Sci. $\quad$ 89, 589-595. https://doi.org/10.3168/jds.S00220302(06)72122-1

Gambín, P., Ceacero, F., Garcia, A.J., Landete-Castillejos, T., Gallego, L., 2017. Patterns of antler consumption reveal osteophagia as a natural mineral resource in key periods for red deer (Cervus elaphus). Eur. J. Wildl. Res. 63, 3-39. https://doi.org/10.1007/s10344017-1095-4

Gebert, C., Verheyden-Tixier, H., 2001. Variations of diet composition of Red Deer (Cervus elaphus L.) in Europe. Mamm. Rev. 31, 189-201. https://doi.org/10.1046/j.13652907.2001.00090.x

Giesemann, M.A., Lewis, A.J., Miller, P.S., Akhter, M.P., 1998. Effects of the reproductive cycle and age on calcium and phosphorus metabolism and bone integrity of sows. J. Anim. Sci. 76, 796-807. https://doi.org/10.2527/1998.763796x

Grasman, B.T., Hellgren, E.C., 1993. Phosphorus nutrition in white-tailed deer: nutrient balance, physiological responses, and antler growth. Ecology 74, 2279-2296.

Green, D.R., Smith, T.M., Bidlack, F.B., Green, G.M., Colman, A.S., Tafforeau, P., 2017. Synchrotron imaging and Markov Chain Monte Carlo reveal tooth mineralization patterns. PLoS One 12, e0186391. https://doi.org/10.1371/journal.pone.0186391 
866 867

868

869

870

871

872

874

875

876

877

878

879

880

881

882

883

884

885

886

887

Griffith, E.M., Schmitt, A.D., Andrews, M.G., Fantle, M.S., 2020. Elucidating modern geochemical cycles at local, regional, and global scales using calcium isotopes. Chem. Geol. 534, 119445. https://doi.org/10.1016/j.chemgeo.2019.119445

Guérin, C., Philippe, M., Vilain, R., 1979. Le gisement Pleistocène supérieur de la grotte de Jaurens à Nespouls, Corrèze, France: historique et généralités. Nouv. Arch. du Muséum D’Histoire Nat. Lyon 17, 11-16.

Gussone, N., Heuser, A., 2016. Biominerals and biomaterial, in: Hoefs, J. (Ed.), Calcium Stable Isotope Geochemistry. Springer, Berlin, Heidelberg, pp. 111-144.

Hadjidakis, D.J., Androulakis, I.I., 2006. Bone remodeling. Ann. N. Y. Acad. Sci. 1092, 385396. https://doi.org/10.1196/annals.1365.035

Harris, R.B., Wall, W.A., Allendorf, F.W., 2002. Genetic consequences of hunting: What do we know and what should we do? Wildl. Soc. Bull. 30, 634-643.

Hassler, A., Martin, J.E., Amiot, R., Tacail, T., Godet, F.A., Allain, R., Balter, V., 2018. Calcium isotopes offer clues on resource partitioning among Cretaceous predatory dinosaurs. Proc. R. Soc. B Biol. Sci. 285, 20180197. https://doi.org/10.1098/rspb.2018.0197

Hearney, A.W., Jennings, T.J., 1983. Annual foods of the Red deer (Cervus elaphus) and the Roe deer (Capreolus capreolus) in the east of England. J. Zool. 201, 565-570.

Heuser, A., 2016. Biomedical Application of Ca Stable Isotopes, in: Hoefs, J. (Ed.), Calcium Stable Isotope Geochemistry. Springer, Berlin, Heidelberg, pp. 247-260.

Heuser, A., Eisenhauer, A., 2008. The calcium isotope composition $\left(\delta^{44 / 40} \mathrm{Ca}\right)$ of NIST SRM 915b and NIST SRM 1486. Geostand. Geoanalytical Res. 32, 311-315. 

https://doi.org/10.1111/j.1751-908X.2008.00877.x

889

890

891

892

893

894

895

896

897

898

899

900

901

902

903

904

905

906

907

908

909

Heuser, A., Eisenhauer, A., 2010. A pilot study on the use of natural calcium isotope $\left({ }^{44} \mathrm{Ca} /{ }^{40} \mathrm{Ca}\right)$ fractionation in urine as a proxy for the human body calcium balance. Bone 46, 889-896. https://doi.org/10.1016/j.bone.2009.11.037

Heuser, A., Eisenhauer, A., Scholz-Ahrens, K.E., Schrezenmeir, J., 2016. Biological fractionation of stable $\mathrm{Ca}$ isotopes in Göttingen minipigs as a physiological model for $\mathrm{Ca}$ homeostasis in humans. Isotopes Environ. Health Stud. 52, 633-648. https://doi.org/10.1080/10256016.2016.1151017

Heuser, A., Frings-Meuthen, P., Rittweger, J., Galer, S.J.G., 2019. Calcium isotopes in human urine as a diagnostic tool for bone loss: Additional evidence for time delays in bone response to experimental bed rest. Front. Physiol. 10, 12. https://doi.org/10.3389/fphys.2019.00012

Heuser, A., Tütken, T., Gussone, N., Galer, S.J.G., 2011. Calcium isotopes in fossil bones and teeth - Diagenetic versus biogenic origin. Geochim. Cosmochim. Acta 75, 3419-3433. https://doi.org/10.1016/j.gca.2011.03.032

Hirata, T., Tanoshima, M., Suga, A., Tanaka, Y., Nagata, Y., Shinohara, A., Chiba, M., 2008. Isotopic analysis of calcium in blood plasma and bone from mouse samples by multiple collector-ICP-mass spectrometry. Anal. Sci. 24, 1501-1507. https://doi.org/10.2116/analsci.24.1501

Hofmann, R.R., 1989. Evolutionary steps of ecophysiological adaptation and diversification of ruminants: a comparative view of their digestive system. Oecologia 78, 443-457. https://doi.org/10.1007/BF02352565 
910

911

912

913

914

915

916

917

918

919

920

921

922

923

924

925

926

927

928

929

930

931 Krausman, P.R.., Bissonette, J.A.., 1977. Bone-chewing behavior of desert mule deer.

Holmden, C., Bélanger, N., 2010. Ca isotope cycling in a forested ecosystem. Geochim. Cosmochim. Acta 74, 995-1015. https://doi.org/10.1016/j.gca.2009.10.020

Jones, K.E., Bielby, J., Cardillo, M., Fritz, S.A., O’Dell, J., Orme, C.D.L., Safi, K., Sechrest, W., Boakes, E.H., Carbone, C., Connolly, C., Cutts, M.J., Foster, J.K., Grenyer, R., Plaster, C.A., Price, S.A., Rigby, E.A., Rist, J., Teacher, A., Bininda-Emonds, O.R.P., Gittleman, J.L., Mace, G.M., Purvis, A., 2009. PanTHERIA: a species-level database of life history, ecology, and geography of extant and recently extinct mammals. Ecology 90:2648.

Karlsson, C., Obrant, K.J., Karlsson, M., 2001. Pregnancy and lactation confer reversible bone loss in humans. Osteoporos. Int. 12, 828-834.

Kjos-Hanssen, O., 1973. Reindeer antlers and what they can tell us about the reindeer $\begin{array}{lllll}\text { population. } & \text { Nor. } & \text { Archaeol. } & \text { Rev. }\end{array}$ https://doi.org/10.1080/00293652.1973.9965188

Klevezal, G.A., Mina, M. V., 1995. Recording structures of mammals : Determination of age and reconstruction of life history. CRC Press.

Kohn, M.J., 2004. Comment: Tooth enamel mineralization in ungulates: Implications for recovering a primary isotopic time-series, by B. H. Passey and T. E. Cerling (2002). Geochim. Cosmochim. Acta 68, 403-405. https://doi.org/10.1016/S00167037(03)00446-0

Kovacs, C.S., Fuleihan, G.E., 2006. Calcium and bone disorders during pregnancy and lactation. Endocrinol. Metab. Clin. 35, 21-51. https://doi.org/10.1016/j.ecl.2005.09.004 

Southwest. Nat. 22, 149-150.

933

934

935

936

937

938

939

940

941

942

943

944

945

946

947

948

949

950

951

952

953

Martin, J.E., Vincent, P., Tacail, T., Khaldoune, F., Jourani, E., Bardet, N., Balter, V., 2017b.

Kruuk, L.E.B., Slate, J., Pemberton, J.M., Brotherstone, S., Guinness, F., Clutton-Brock, T., 2002. Antler size in red deer: Heritability and selection but no evolution. Evolution (N. Y). 56, 1683-1695. https://doi.org/10.1111/j.0014-3820.2002.tb01480.x

Li, C., 2013. Histogenetic aspects of deer antler development. Front. Biosci. 5, 479-489.

Li, Q., Nava, A., Reynard, L.M., Thirlwall, M., Bondioli, L., Müller, W., 2020. Spatiallyresolved $\mathrm{Ca}$ isotopic and trace element variations in human deciduous teeth record diet and physiological change. Environ. Archaeol. 1-10. https://doi.org/10.1080/14614103.2020.1758988

Li, Q., Thirlwall, M., Müller, W., 2016. Ca isotopic analysis of laser-cut microsamples of (bio)apatite without chemical purification. Chem. Geol. 422, 1-12. https://doi.org/10.1016/j.chemgeo.2015.12.007

Marie, W., 1982. Antlers-a mineral source in Rangifer. Acta Zool. 63, 7-10.

Martin, J.E., Tacail, T., Adnet, S., Girard, C., Balter, V., 2015. Calcium isotopes reveal the trophic position of extant and fossil elasmobranchs. Chem. Geol. 415, 118-125. https://doi.org/10.1016/j.chemgeo.2015.09.011

Martin, J.E., Tacail, T., Balter, V., 2017a. Non-traditional isotope perspectives in vertebrate palaeobiology. Palaeontology 60, 485-502. https://doi.org/10.1111/pala.12300

Martin, J.E., Tacail, T., Cerling, T.E., Balter, V., 2018. Calcium isotopes in enamel of modern and Plio-Pleistocene East African mammals. Earth Planet. Sci. Lett. 503, 227-235. https://doi.org/10.1016/j.eps1.2018.09.026 
954 955

956 957 958 Calcium isotopic evidence for vulnerable marine ecosystem structure prior to the $\mathrm{K} / \mathrm{Pg}$ extinction. Curr. Biol. 1-4. https://doi.org/10.1016/j.cub.2017.04.043

Mathiesen, S.D., Haga, E., Kaino, T., Tyler, N.J.C., 2000. Diet composition, rumen papillation and maintenance of carcass mass in female Norwegian reindeer (Rangifer tarandus tarandus) in winter. J. Zool. 251, $129-138$. https://doi.org/10.1017/S0952836900005136

Melin, A.D., Crowley, B.E., Brown, S.T., Wheatley, P. V., Moritz, G.L., Yit Yu, F.T., Bernard, H., DePaolo, D.J., Jacobson, A.D., Dominy, N.J., 2014. Calcium and carbon stable isotope ratios as paleodietary indicators. Am. J. Phys. Anthropol. 154, 633-643. https://doi.org/10.1002/ajpa.22530

Merceron, G., Berlioz, E., Vonhof, H., Green, D., Garel, M., Tütken, T., 2021. Tooth tales told by dental diet proxies: An alpine community of sympatric ruminants as a model to decipher the ecology of fossil fauna. Palaeogeogr. Palaeoclimatol. Palaeoecol. 562, 110077. https://doi.org/10.1016/j.palaeo.2020.110077

Miller, F.L., 1972. Eruption and attrition of mandibular teeth in barren-ground caribou. J. Wildl. Manage. 606-612.

Mitchell, B., McCowan, D., Nicholson, I.A., 1976. Annual cycles of body weight and condition in Scottish Red deer, Cervus elaphus. J. Zool. 180, 107-127. https://doi.org/10.1111/j.1469-7998.1976.tb04667.x

Morgan, J.L.L., Skulan, J.L., Gordon, G.W., Romaniello, S.J., Smith, S.M., Anbar, A.D., 2012. Rapidly assessing changes in bone mineral balance using natural stable calcium isotopes. Proc. Natl. Acad. Sci. U.S.A. 109, 9989-9994. https://doi.org/10.1073/pnas.1119587109 42 
977 Moynier, F., Fujii, T., 2017. Calcium isotope fractionation between aqueous compounds 978 relevant to low-temperature geochemistry, biology and medicine. Sci. Rep. 7, 44255. 980 981 https://doi.org/10.1038/srep44255

Muir, P.D., Sykes, A.R., Barrell, G.K., 1987a. Calcium metabolism in red deer (Cervus elaphus) offered herbages during antlerogenesis: Kinetic and stable balance studies. J. Agric. Sci. 109, 357-364. https://doi.org/10.1017/S0021859600080783

Muir, P.D., Sykes, A.R., Barrell, G.K., 1987b. Growth and mineralisation of antlers in red deer (Cervus elaphus). New Zeal. J. Agric. Res. 30, 305-315. https://doi.org/10.1080/00288233.1987.10421889

Müller, W., Nava, A., Evans, D., Rossi, P.F., Alt, K.W., Bondioli, L., 2019. Enamel mineralization and compositional time-resolution in human teeth evaluated via histologically-defined LA-ICPMS profiles. Geochim. Cosmochim. Acta 255, 105-126. https://doi.org/10.1016/j.gca.2019.03.005

Passey, B.H., Cerling, T.E., 2002. Tooth enamel mineralization in ungulates: Implications for recovering a primary isotopic time-series. Geochim. Cosmochim. Acta 66, 3225-3234. https://doi.org/10.1016/S0016-7037(02)00933-X

Pasteris, J.D., Wopenka, B., Valsami-Jones, E., 2008. Bone and tooth mineralization: Why apatite? Elements 4, 97-104. https://doi.org/10.2113/GSELEMENTS.4.2.97

Pellerin, M., Bonenfant, C., Garel, M., Chevrier, T., Queney, G., Klein, F., Michallet, J., 2014. Dynamique de la population de cerfs du domaine national de Chambord: Analyse temporelle des indicateurs de changement écologique (ICE). Rapp. d'expertise ONCFS.

Ramberg Jr, C.F., Mayer, G.P., Kronfeld, D.S., Phang, J.M., Berman, M., 1970. Calcium 
kinetics in cows during late pregnancy, parturition, and early lactation. Am. J. Physiol.

1000 Content 219, 1166-1177.

1001 Redjadj, C., Darmon, G., Maillard, D., Chevrier, T., Bastianelli, D., Verheyden, H., Loison, 1002 A., Saïd, S., 2014. Intra- and interspecific differences in diet quality and composition in a 1003 large herbivore community. PLoS One 9. https://doi.org/10.1371/journal.pone.0084756

1004 Reynard, L.M., Henderson, G.M., Hedges, R.E.M., 2010. Calcium isotope ratios in animal 1005 and human bone. Geochim. Cosmochim. Acta 74, 3735-3750. 1006 https://doi.org/10.1016/j.gca.2010.04.002

1007 Rolf, H.J., Enderle, A., 1999. Hard fallow deer antler: A living bone till antler casting? Anat. 1008 1009 Rec. 255, 69-77. https://doi.org/10.1002/(SICI)1097-0185(19990501)255:1<69::AIDAR8 $>3.0 . C O ; 2-\mathrm{R}$

1010 1011 
1021

1022

1023

1024 Stevens, R.E., Balasse, M., O’Connell, T.C., 2011. Intra-tooth oxygen isotope variation in a 1025 known population of red deer: Implications for past climate and seasonality 1026 reconstructions. Palaeogeogr. Palaeoclimatol. Palaeoecol. 301, 64-74. 1027 1028 1029 1030 1031 1032 1033 1034 1035 1036 1037 1038

1039 Tacail, T., Martin, J.E., Arnaud-Godet, F., Thackeray, J.F., Cerling, T.E., Braga, J., Balter, V., 1040 2019. Calcium isotopic patterns in enamel reflect different nursing behaviors among 1041 South African early hominins. Sci. Adv. 5, eaax3250. 1042

Grün, R., James, H.F., Moncel, M., Williams, I.S., Wood, R., Arora, M., 2018. Wintertime stress, nursing, and lead exposure in Neanderthal children. Sci. Adv. 4, eaau9483. https://doi.org/10.1016/j.palaeo.2010.12.021

Storms, D., Aubry, P., Hamann, J.-L., Saïd, S., Fritz, H., Saint-Andrieux, C., Klein, F., 2008. Seasonal variation in diet composition and similarity of sympatric red deer Cervus elaphus and roe deer Capreolus capreolus. Wildlife Biol. 14, 237-250. https://doi.org/10.2981/0909-6396(2008)14[237:svidca]2.0.co;2

Tacail, T., 2017. Calcium isotope physiology in mammals. PhD thesis. Université de Lyon.

Tacail, T., Albalat, E., Télouk, P., Balter, V., 2014. A simplified protocol for measurement of Ca isotopes in biological samples. J. Anal. At. Spectrom. 29, 529. https://doi.org/10.1039/c3ja50337b

Tacail, T., Le Houedec, S., Skulan, J.L., 2020. New frontiers in calcium stable isotope geochemistry: Perspectives in present and past vertebrate biology. Chem. Geol. https://doi.org/https://doi.org/10.1016/j.chemgeo.2020.119471 https://doi.org/10.1126/sciadv.aax3250 
1043 Tacail, T., Télouk, P., Balter, V., 2016. Precise analysis of calcium stable isotope variations in 1044 1045 biological apatites using laser ablation MC-ICPMS. J. Anal. At. Spectrom. 31, 152-162. https://doi.org/10.1039/C5JA00239G

1046 Tacail, T., Thivichon-Prince, B., Martin, J.E., Charles, C., Viriot, L., Balter, V., 2017. 1047 Assessing human weaning practices with calcium isotopes in tooth enamel. Proc. Natl. 1048 Acad. Sci. U.S.A. 114, 6268-6273. https://doi.org/10.1073/pnas.1704412114

sex
F
F

Table 1. Body mass data of red deer from Bauges NRP

$\begin{array}{lllll}\text { mean } & \text { sd } & \mathrm{n} & \text { lower } & \text { upper } \\ 98.05 & 12.82 & 447 & 81.58 & 114.52 \\ 52.00 & 8.75 & 223 & 40.73 & 63.27\end{array}$




$\begin{array}{lllllll}\text { F } & \text { SA } & 77.21 & 9.30 & 102 & 65.15 & 89.27 \\ \text { M } & \text { A } & 150.71 & 27.90 & 457 & 114.87 & 186.56 \\ \text { M } & \text { J } & 56.40 & 8.70 & 218 & 45.20 & 67.60 \\ \text { M } & \text { SA } & 96.05 & 13.66 & 187 & 78.44 & 113.66\end{array}$

1064 NOTE. This table shows the total body mass data $[\mathrm{kg}]$ recorded on 1634 specimens of red 1065 deer from Bauges NRP. Age classes referred as adult (A), subadult (SA) and juvenile (J).

\section{Figures and captions}

1068 Figure 1. Mass dependency

1069 Three isotope plot: $\delta^{43 / 42} \mathrm{Ca}$ as a function of $\delta^{44 / 42} \mathrm{Ca}(\%$, expressed relatively to ICP Ca Lyon) 1070 for all samples and standards analyzed for $\mathrm{Ca}$ isotope compositions in this study. The 1071 regression line of these $\mathrm{Ca}$ isotope compositions (central blue line) has a $\mathrm{y}$-axis intercept of $10720.006 \pm 0.015$ (\%o, 2 s.e.), indistinguishable from theoretical $0 \%$ intercept. The slope value of 1073 this line is $0.509 \pm 0.016$ ( 2 s.e.), indistinguishable from the 0.507 slope predicted by the 1074 exponential mass-dependent fractionation law (black dotted line). Error bars at the bottom 1075 right are average 2 s.d. for $\delta^{43 / 42} \mathrm{Ca}$ and $\delta^{44 / 42} \mathrm{Ca}$. The two most external lines (blue) delimit the 1076 prediction interval whereas the two lines (red) around the central line correspond to the $95 \%$ 1077 confidence interval of the regression line.

1078 Figure 2. Sex and body mass control over bone $\delta^{44 / 42}$ Ca values

1079 Bone $\delta^{44 / 42} \mathrm{Ca}$ values of adult red deer specimens ( $\geq$ three years old) from Bauges NRP plotted 1080 in function of their total body mass. The average double standard error of these measures 1081 (Mean 2SE in the graph) is represented at the bottom right of the graph. The two vertical 
1082 dotted lines mark the limits of body mass (65 and $105 \mathrm{~kg}$ ) expected from females which 1083 supposedly gave birth and lactate during the last birth season preceding their death. Red deer 1084 silhouettes are modified from pictures of the public domain accessible in the following 1085 website: www.phylopic.org.

1086 Figure 3. Sex and age control over bone $\delta^{44 / 42} \mathrm{Ca}$ values

1087 Bone $\delta^{44 / 42} \mathrm{Ca}$ values of red deer from Bauges NRP grouped by sex and age categories. Adult 1088 red deer ( $\geq$ three years old) are represented by dots and sub-adults (two years old) by 1089 triangles. Boxplots are plotted from adult male and lactating female data. The degree of 1090 significance of the difference between these two groups is represented with stars $(*)$, with two 1091 stars indicating a Wilcoxon rank-sum test: $p$-value $<0.01$. The average double standard error 1092 of these measures (Mean 2SE in the graph) is represented at the bottom right of the graph. 1093 Red deer silhouettes are modified from pictures of the public domain accessible in the 1094 following website: www.phylopic.org.

1095 Figure 4. Antler Ca isotopic composition

1096 Intra-individual variability of mandible and antler bone $\delta^{44 / 42} \mathrm{Ca}$ values from the SPB 1097 specimen. In this graph antler micro-samples are plotted in function of their original position 1098 from the sampled antler displayed in photo. Blue error bars represent the 2 s.e. intervals of 1099 each sample. The horizontal black and red lines represent respectively the mean mandible 1100 bone $\delta^{44 / 42} \mathrm{Ca}$ value of the specimen and the limits of its confidence interval ( \pm 2 s.e).

1101 Figure 5. Enamel and bone $\delta^{44 / 42}$ Ca variability of modern red deer

1102 The $\delta^{44 / 42} \mathrm{Ca}$ values from bone and enamel micro-samples of $\mathrm{AB}$ and JVB specimens (modern 1103 red deer, Bauges NRP). The horizontal black and red lines represent respectively the mean 1104 bone $\delta^{44 / 42} \mathrm{Ca}$ value of each specimen and the limits of their confidence interval ( \pm 2 s.e). 
1105 Micro-samples from DP4, M1, M2 and M3 teeth are respectively represented by purple

1106 diamonds, red points, blue squares and green triangles. Dashed orange and cyan ellipses

1107 respectively emphasize periods during which mineral licking and osteophagia events are

1108 suspected. Error bares represent the 2 s.e. intervals for each sample. The age model used for

1109 temporally anchor enamel micro-samples is described in section 2.4 and is extrapolated from

1110 Brown and Chapman (1991a), with the only exception of enamel mineralizing in utero for

1111 which ages are arbitrary. Teeth mineralization timings which served this model are displayed

1112 at the bottom of the graph. Note that despite our micro-sampling procedure time averaging

1113 likely affects each of these enamel micro-samples (see appendix). Red deer silhouettes are

1114 modified from pictures of the public domain accessible in the following website:

1115 www.phylopic.org.

1116 Figure 6. Enamel $\delta^{44 / 42}$ Ca variability of fossil reindeer

1117 The $\delta^{44 / 42} \mathrm{Ca}$ values from bone and enamel micro-samples of AJ, JVJ, ISO M1 and ISO DP4

1118 specimens (fossil reindeer). Note that ISO M1 and ISO DP4 are two distinct specimens that

1119 have been merged in one graph only for visual convenience. Micro-samples from DP4, M1,

1120 M2, M3 and P4 teeth are respectively represented by purple diamonds, red points, blue

1121 squares, green triangles and inverted yellow triangles. The dashed orange ellipse emphasizes a

1122 period during which mineral licking events are suspected. Dotted boxes contain points

1123 identified as providing accurate trophic information (see section 4.3). Error bares represent

1124 the 2 s.e. intervals of each sample. The age model used for temporally anchor enamel micro-

1125 samples is described in section 2.4 and is extrapolated from Brown and Chapman, 1991a,

1126 with the only exception of enamel mineralizing in utero for which ages are arbitrary. Teeth

1127 mineralization timings which served this model are displayed at the bottom of the graph. Note

1128 that despite our micro-sampling procedure time averaging likely affects each of these enamel 
1129 micro-samples (see appendix). Reindeer silhouettes are pictures from the public domain

1130 accessible in the following website: www.phylopic.org.

\section{Appendix}

\section{Bone and enamel mineralization patterns}

1133 This appendix further describes the nature and length of mineralization we consider for bones

1134 and teeth. This text include the following references: (Ewbank et al., 1964; Biewener, 1990;

1135 Brown and Chapman, 1991a, 1991b; Smith, 1998; Fricke et al., 1998; Passey and Cerling,

1136 2002; Kohn, 2004; Hadjidakis and Androulakis, 2006; Pasteris et al., 2008; Stevens et al.,

1137 2011; Blaine et al., 2015; Tacail, 2017; Trayler and Kohn, 2017; Green et al., 2017; Smith et

1138 al., 2018).

1139 Figure S1. Bone box model

1140 This box model describes the evolution of a conceptual bone reservoir representing $1.2 \times 10^{6}$

$1141 \mathrm{mg}$ of $\mathrm{Ca}$ (in red) exchanging with an infinite reservoir (in purple) through $500 \mathrm{mg}^{-\mathrm{d}^{-1}}$ of input 1142 and output $\mathrm{Ca}$ fluxes. Bone starts with a $\delta^{44 / 42} \mathrm{Ca}$ value of $-0.5 \%$ and the infinite box is set to $11430 \%$. Time is given in days. These reservoir sizes are inspired from the human model 1144 described in Tacail (2017).

1145 Table S1. Calcium isotope composition and supplementary information of red deer

1146 This table includes all $\mathrm{Ca}$ isotope composition data collected on red deer in this study as well

1147 as additional specimen and sample details (e.g. sample ID, sampling method, body mass).

1148 When both data were available, total body mass was in average 1.28 bigger for males and

11491.42 bigger for females than their respective gutted body mass. We applied this factor to

1150 calculate the total body mass when only gutted body mass data were available. Total body 1151 mass format is in bold when weighted post mortem (i.e. not converted from gutted body 
1152 mass). Age format is in bold when directly recorded, other age values are inferred from tooth 1153 eruption and attrition stages (Brown and Chapman, 1991a, 1991b).

1154 Table S2. Calcium isotope composition and supplementary information of reindeer

1155 This table includes all $\mathrm{Ca}$ isotope composition data collected on reindeer in this study as well 1156 as additional specimen and sample details (e.g. sample ID, sampling method).

1157 Table S3. Calcium isotope composition of reference materials

1158 This table includes all Ca isotope composition data collected in this study on SRM 1486 1159 (NIST) and IAPSO (OSIL). Data of the same reference materials from previous studies are 1160 summarized for comparison.

1161 Table S4. Sample elemental composition

1162 Sample elemental composition of 26 major and trace elements of herbaceous remains, 1163 mandibles and antlers. 


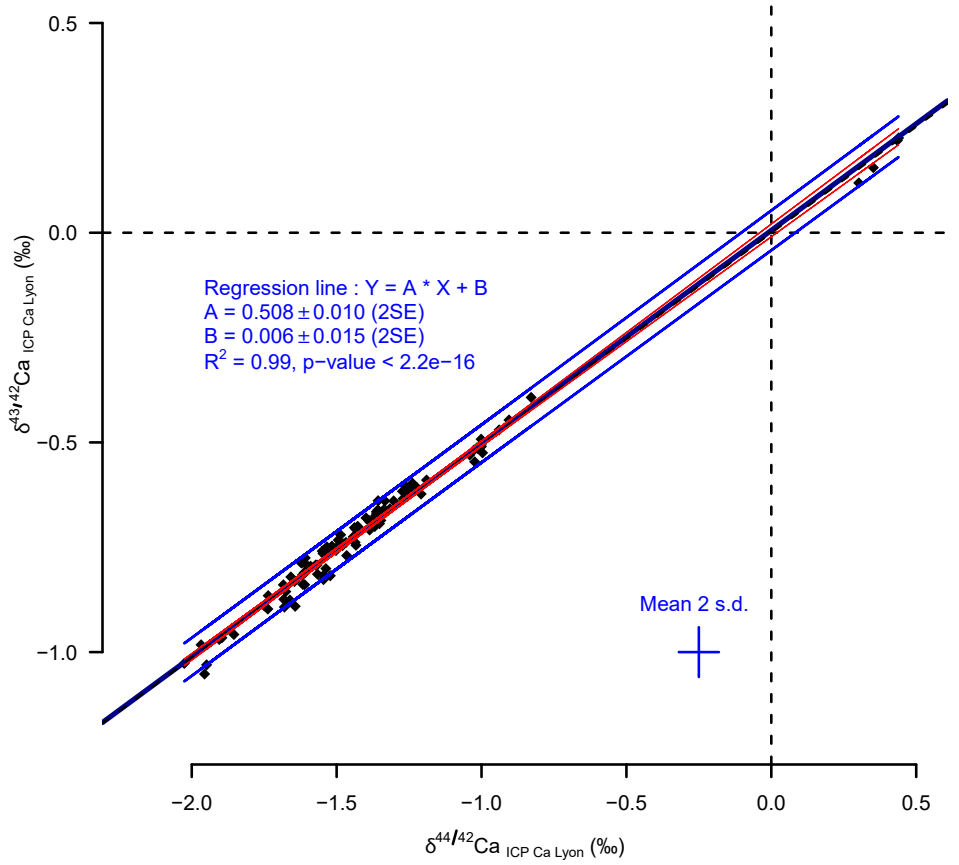




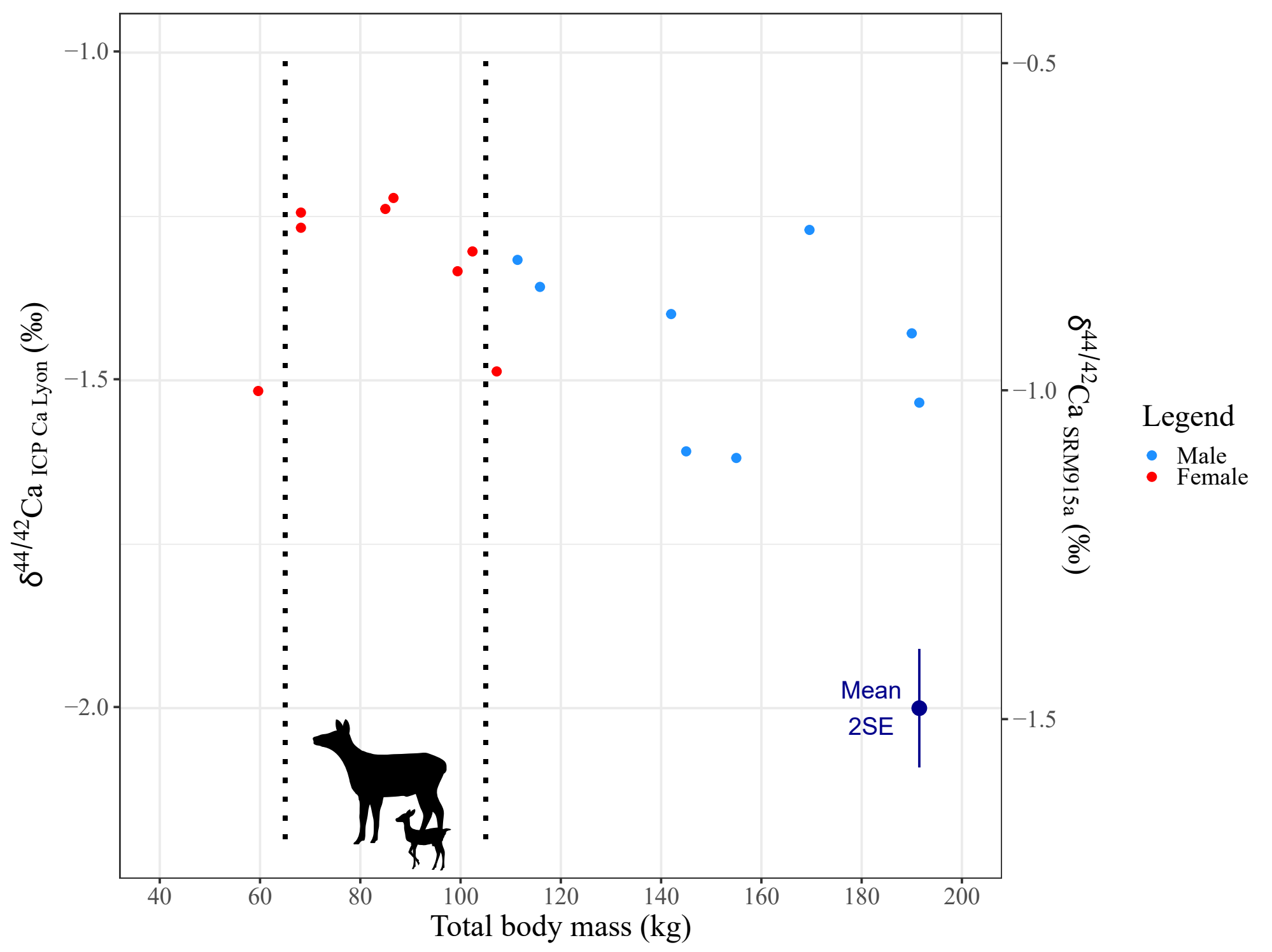




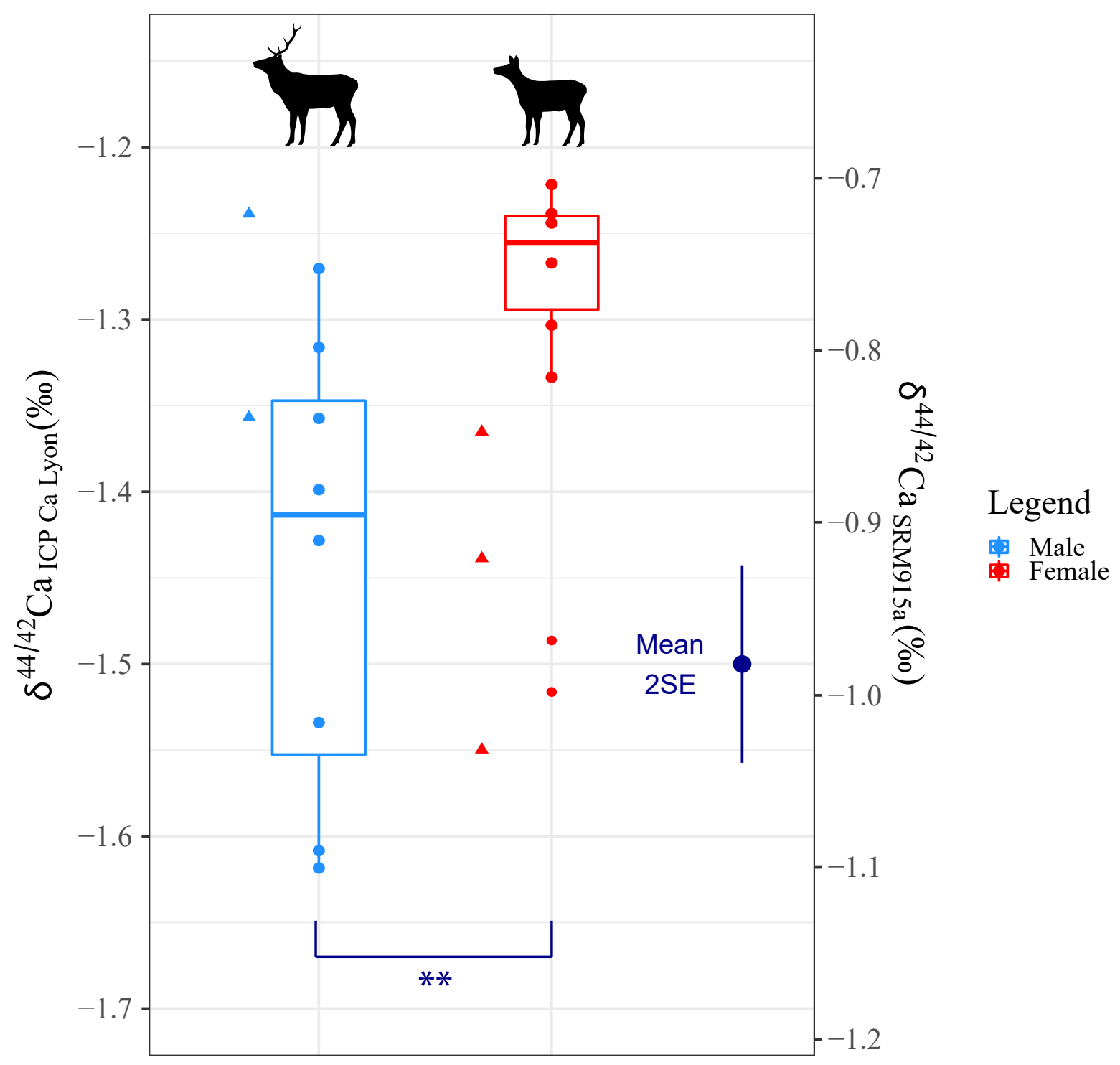




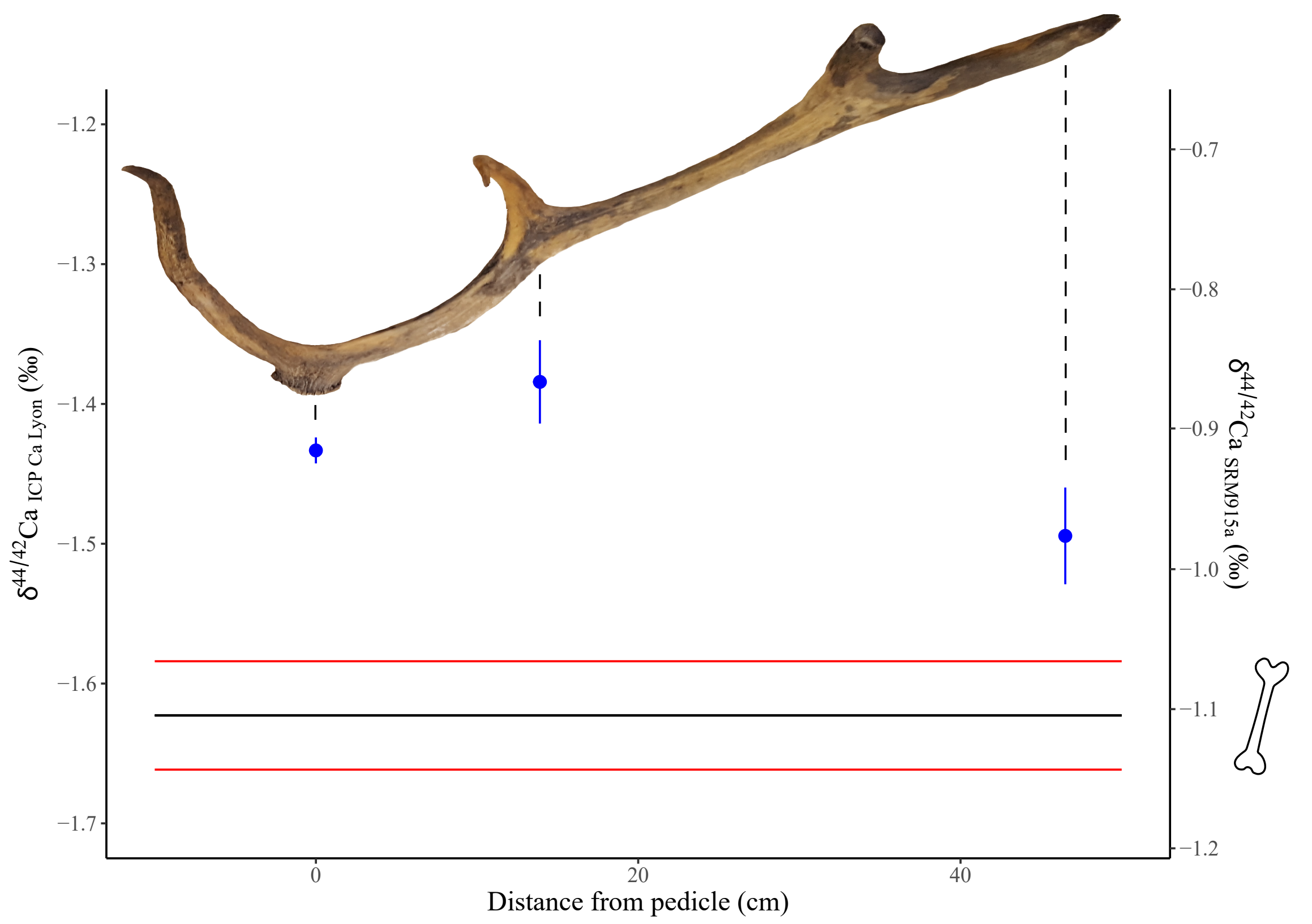



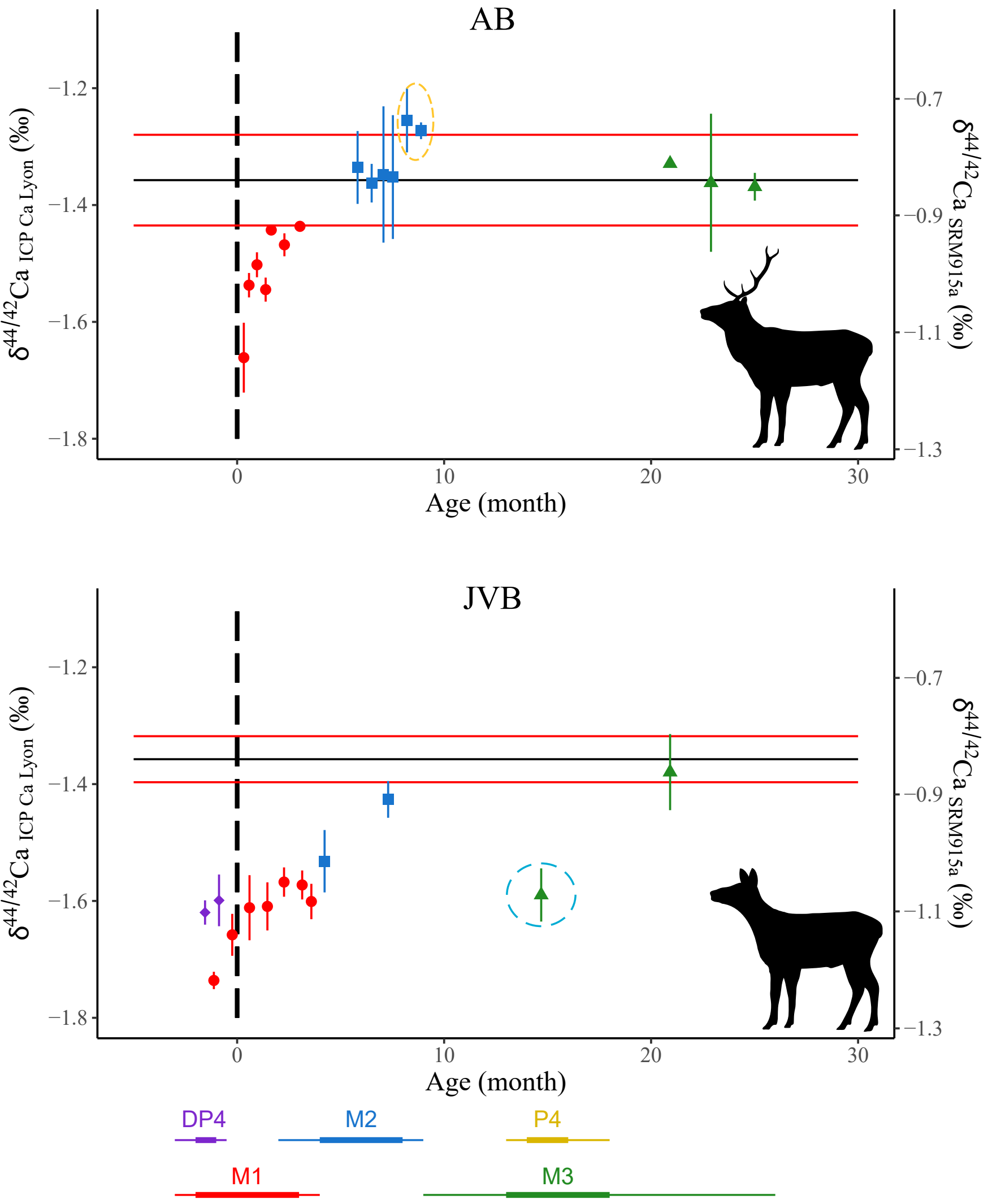


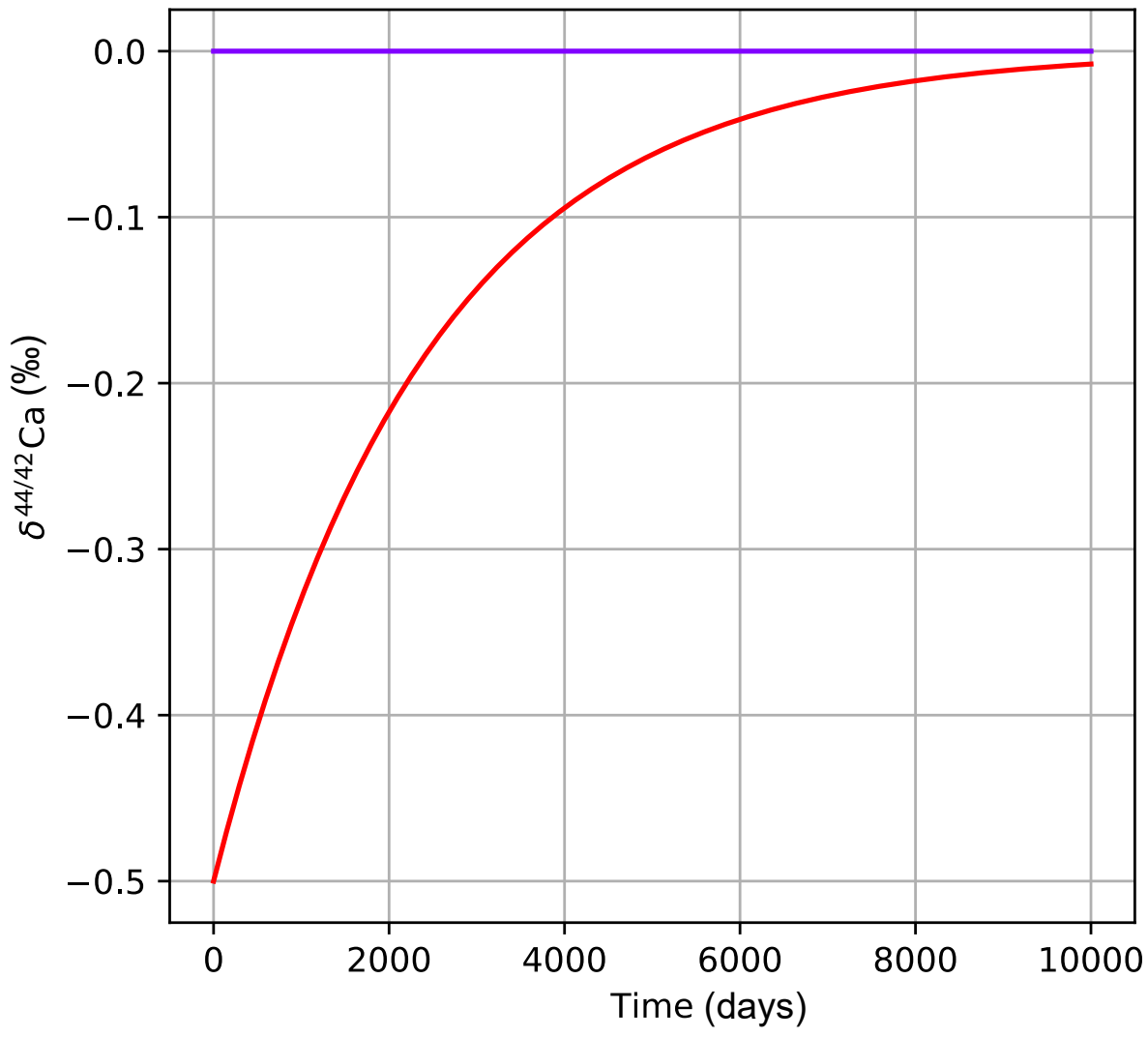




$\begin{array}{lllllll}\text { sex } & \text { age } & \text { mean } & \text { sd } & \mathrm{n} & \text { lower } & \text { upper } \\ \text { F } & \text { A } & 98.05 & 12.82 & 447 & 81.58 & 114.52 \\ \text { F } & \text { J } & 52.00 & 8.75 & 223 & 40.73 & 63.27 \\ \text { F } & \text { SA } & 77.21 & 9.30 & 102 & 65.15 & 89.27 \\ \text { M } & \text { A } & 150.71 & 27.90 & 457 & 114.87 & 186.56 \\ \text { M } & \text { J } & 56.40 & 8.70 & 218 & 45.20 & 67.60 \\ \text { M } & \text { SA } & 96.05 & 13.66 & 187 & 78.44 & 113.66\end{array}$


Collection id Labname Origin Genus Species Tissue

\begin{tabular}{|c|c|c|c|c|c|}
\hline UP-15CE0104 & \multicolumn{2}{|c|}{ 15CE0104 osBauges } & Cervus & elaphus & mandibular bone \\
\hline UP-15CE0106 & \multicolumn{2}{|c|}{ 15CE0106 osBauges } & Cervus & elaphus & mandibular bone \\
\hline UP-15CE0140 & \multicolumn{2}{|c|}{ 15CE0140 osBauges } & Cervus & elaphus & mandibular bone \\
\hline UP-15CE2616 & \multicolumn{2}{|c|}{ 15CE2616 os Bauges } & Cervus & elaphus & mandibular bone \\
\hline UP-15CE2620 & \multicolumn{2}{|c|}{ 15CE2620 os Bauges } & Cervus & elaphus & mandibular bone \\
\hline UP-15CE2655 & \multicolumn{2}{|c|}{ 15CE2655 osBauges } & Cervus & elaphus & mandibular bone \\
\hline UP-15CE3523 & \multicolumn{2}{|c|}{ 15CE3523 osBauges } & Cervus & elaphus & mandibular bone \\
\hline UP-15CE4526 & \multicolumn{2}{|c|}{ 15CE4526 os Bauges } & Cervus & elaphus & mandibular bone \\
\hline UP-15CE4821 & \multicolumn{2}{|c|}{ 15CE4821 os Bauges } & Cervus & elaphus & mandibular bone \\
\hline UP-15CE4823 & \multicolumn{2}{|c|}{ 15CE4823 os Bauges } & Cervus & elaphus & mandibular bone \\
\hline UP-15CE4825 & \multicolumn{2}{|c|}{ 15CE4825 os Bauges } & Cervus & elaphus & mandibular bone \\
\hline UP-15CE4929 & \multicolumn{2}{|c|}{ 15CE4929 os Bauges } & Cervus & elaphus & mandibular bone \\
\hline UP-15CE4951 & \multicolumn{2}{|c|}{ 15CE4951 os Bauges } & Cervus & elaphus & mandibular bone \\
\hline UP-15CE5028 & \multicolumn{2}{|c|}{ 15CE5028 os Bauges } & Cervus & elaphus & mandibular bone \\
\hline UP-15CE5519 & \multicolumn{2}{|c|}{ 15CE5519 os Bauges } & Cervus & elaphus & mandibular bone \\
\hline UP-15CE5616 & \multicolumn{2}{|c|}{ 15CE5616 os Bauges } & Cervus & elaphus & mandibular bone \\
\hline UP-15CE5795 & \multicolumn{2}{|c|}{ 15CE5795 os Bauges } & Cervus & elaphus & mandibular bone \\
\hline UP-15CE5837 & \multicolumn{2}{|c|}{ 15CE5837 os Bauges } & Cervus & elaphus & mandibular bone \\
\hline UP-15CE7104 & \multicolumn{2}{|c|}{ 15CE7104 os Bauges } & Cervus & elaphus & mandibular bone \\
\hline UP-15CE5672 & AB M1-3 & Bauges & Cervus & elaphus & enamel \\
\hline UP-15CE5672 & AB M1-4 & Bauges & Cervus & elaphus & enamel \\
\hline UP-15CE5672 & AB M1-5 & Bauges & Cervus & elaphus & enamel \\
\hline UP-15CE5672 & AB M1-11 & Bauges & Cervus & elaphus & enamel \\
\hline UP-15CE5672 & AB M1-12 & Bauges & Cervus & elaphus & enamel \\
\hline UP-15CE5672 & AB M1-13 & Bauges & Cervus & elaphus & enamel \\
\hline UP-15CE5672 & AB M1-7 & Bauges & Cervus & elaphus & enamel \\
\hline UP-15CE5672 & AB M2-1 & Bauges & Cervus & elaphus & enamel \\
\hline UP-15CE5672 & AB M2-2 & Bauges & Cervus & elaphus & enamel \\
\hline UP-15CE5672 & AB M2-3 & Bauges & Cervus & elaphus & enamel \\
\hline UP-15CE5672 & $\mathrm{AB} M 2-4$ & Bauges & Cervus & elaphus & enamel \\
\hline UP-15CE5672 & AB M2-5 & Bauges & Cervus & elaphus & enamel \\
\hline UP-15CE5672 & AB M2-6 & Bauges & Cervus & elaphus & enamel \\
\hline UP-15CE5672 & AB M3-1 & Bauges & Cervus & elaphus & enamel \\
\hline UP-15CE5672 & AB M3-2 & Bauges & Cervus & elaphus & enamel \\
\hline UP-15CE5672 & AB M3-3 & Bauges & Cervus & elaphus & enamel \\
\hline UP-15CE5672 & $A B$ os & Bauges & Cervus & elaphus & mandibule bone \\
\hline UP-15CE3734 & JVB DP4-1 & Bauges & Cervus & elaphus & enamel \\
\hline UP-15CE3734 & JVB DP4-2 & Bauges & Cervus & elaphus & enamel \\
\hline UP-15CE3734 & JVB M1-1 & Bauges & Cervus & elaphus & enamel \\
\hline UP-15CE3734 & JVB M1-2 & Bauges & Cervus & elaphus & enamel \\
\hline UP-15CE3734 & JVB M1-3 & Bauges & Cervus & elaphus & enamel \\
\hline UP-15CE3734 & JVB M1-4 & Bauges & Cervus & elaphus & enamel \\
\hline UP-15CE3734 & JVB M1-5 & Bauges & Cervus & elaphus & enamel \\
\hline UP-15CE3734 & JVB M1-6 & Bauges & Cervus & elaphus & enamel \\
\hline UP-15CE3734 & JVB M1-7 & Bauges & Cervus & elaphus & enamel \\
\hline UP-15CE3734 & JVB M2-1 & Bauges & Cervus & elaphus & enamel \\
\hline UP-15CE3734 & JVB M2-2 & Bauges & Cervus & elaphus & enamel \\
\hline UP-15CE3734 & JVB M3-1 & Bauges & Cervus & elaphus & enamel \\
\hline
\end{tabular}




$\begin{array}{llllll}\text { UP-15CE3734 } & \text { JVB M3-2 } & \text { Bauges } & \text { Cervus } & \text { elaphus } & \text { enamel } \\ \text { UP-15CE3734 } & \text { JVB os } & \text { Bauges } & \text { Cervus } & \text { elaphus } & \text { mandibule bone } \\ \text { MHNL-50002207 } & \text { SPB B1 } & \text { Europe } & \text { Cervus } & \text { elaphus } & \text { antler bone } \\ \text { MHNL-50002207 } & \text { SPB B2 } & \text { Europe } & \text { Cervus } & \text { elaphus } & \text { antler bone } \\ \text { MHNL-50002207 } & \text { SPB B3 } & \text { Europe } & \text { Cervus } & \text { elaphus } & \text { antler bone } \\ \text { MHNL-50002207 } & \text { SPB os } & \text { Europe } & \text { Cervus } & \text { elaphus } & \text { mandibule bone }\end{array}$




\begin{tabular}{|c|c|c|c|}
\hline Sampling technique & Age [year] & Sex & th.date $[\mathrm{m} / \mathrm{c} \quad$ Gutted.weight $[\mathrm{kg}]$ \\
\hline handed drill & $\geq 3$ & female & 10/31/2015 61 \\
\hline handed drill & $\geq 3$ & male & 10/18/2015 87 \\
\hline handed drill & $\geq 3$ & male & 12/06/2015 142 \\
\hline handed drill & $\geq 3$ & male & 10/26/2015 na \\
\hline handed drill & $\geq 3$ & male & $11 / 22 / 2015149.5$ \\
\hline handed drill & $\geq 3$ & male & 10/24/2015 na \\
\hline handed drill & 2 & female & 10/25/2015 na \\
\hline handed drill & $\geq 3$ & female & 11/08/2015 72.1 \\
\hline handed drill & $\geq 3$ & female & 10/22/2015 42 \\
\hline handed drill & $\geq 3$ & female & $11 / 15 / 201570$ \\
\hline handed drill & $\geq 3$ & female & $10 / 22 / 201548$ \\
\hline handed drill & $\geq 3$ & female & $10 / 22 / 201548$ \\
\hline handed drill & $\geq 3$ & female & $11 / 22 / 201575.5$ \\
\hline handed drill & 2 & female & 11/01/2015 na \\
\hline handed drill & 2 & male & $10 / 01 / 201570$ \\
\hline handed drill & $\geq 3$ & male & $11 / 12 / 2015132.5$ \\
\hline handed drill & 2 & male & 10/27/2015 na \\
\hline handed drill & $\geq 3$ & male & $11 / 15 / 2015122.5$ \\
\hline handed drill & $\geq 3$ & female & 10/31/2015 na \\
\hline edge-drilling procedure & $\geq 3$ & male & $12 / 20 / 201590.5$ \\
\hline edge-drilling procedure & $\geq 3$ & male & $12 / 20 / 201590.5$ \\
\hline edge-drilling procedure & $\geq 3$ & male & $12 / 20 / 201590.5$ \\
\hline edge-drilling procedure & $\geq 3$ & male & $12 / 20 / 201590.5$ \\
\hline edge-drilling procedure & $\geq 3$ & male & $12 / 20 / 201590.5$ \\
\hline edge-drilling procedure & $\geq 3$ & male & $12 / 20 / 201590.5$ \\
\hline edge-drilling procedure & $\geq 3$ & male & $12 / 20 / 201590.5$ \\
\hline edge-drilling procedure & $\geq 3$ & male & $12 / 20 / 201590.5$ \\
\hline edge-drilling procedure & $\geq 3$ & male & $12 / 20 / 201590.5$ \\
\hline edge-drilling procedure & $\geq 3$ & male & $12 / 20 / 201590.5$ \\
\hline edge-drilling procedure & $\geq 3$ & male & $12 / 20 / 201590.5$ \\
\hline edge-drilling procedure & $\geq 3$ & male & $12 / 20 / 201590.5$ \\
\hline edge-drilling procedure & $\geq 3$ & male & $12 / 20 / 201590.5$ \\
\hline edge-drilling procedure & $\geq 3$ & male & $12 / 20 / 201590.5$ \\
\hline edge-drilling procedure & $\geq 3$ & male & $12 / 20 / 201590.5$ \\
\hline edge-drilling procedure & $\geq 3$ & male & $12 / 20 / 201590.5$ \\
\hline handed drill & $\geq 3$ & male & $12 / 20 / 201590.5$ \\
\hline outer-drilling procedure & 2 & female & 10/17/2015 70 \\
\hline outer-drilling procedure & 2 & female & 10/17/201570 \\
\hline edge-drilling procedure & 2 & female & $10 / 17 / 201570$ \\
\hline edge-drilling procedure & 2 & female & $10 / 17 / 201570$ \\
\hline edge-drilling procedure & 2 & female & 10/17/201570 \\
\hline edge-drilling procedure & 2 & female & 10/17/201570 \\
\hline edge-drilling procedure & 2 & female & 10/17/2015 70 \\
\hline edge-drilling procedure & 2 & female & $10 / 17 / 201570$ \\
\hline edge-drilling procedure & 2 & female & $10 / 17 / 201570$ \\
\hline outer-drilling procedure & 2 & female & $10 / 17 / 201570$ \\
\hline outer-drilling procedure & 2 & female & 10/17/2015 70 \\
\hline outer-drilling procedure & 2 & female & $10 / 17 / 201570$ \\
\hline
\end{tabular}




$\begin{array}{lllll}\text { outer-drilling procedure } & \mathbf{2} & \text { female } & 10 / 17 / 2015 & 70 \\ \text { handed drill } & \mathbf{2} & \text { female } & 10 / 17 / 2015 & 70 \\ \text { handed drill } & \geq 3 & \text { male } & \text { na } & \text { na } \\ \text { handed drill } & \geq 3 & \text { male } & \text { na } & \text { na } \\ \text { handed drill } & \geq 3 & \text { male } & \text { na } & \text { na } \\ \text { handed drill } & \geq 3 & \text { male } & \text { na } & \text { na }\end{array}$




\begin{tabular}{|c|c|c|c|c|}
\hline \multirow{2}{*}{ total.body.mass [kg] } & $n$ & & \multicolumn{2}{|c|}{ rel to ICP Ca Lyon } \\
\hline & Mean $\delta^{44 / 42} \mathrm{Ca}$ & Mean $\delta^{43 / 42} \mathrm{Ca}$ & Mean $\delta^{44 / 43} \mathrm{Ca}$ & 2 s.d. $\delta^{44 / 42} \mathrm{Ca}$ \\
\hline 86.622 & -1.22 & -0.61 & -0.61 & 0.04 \\
\hline 111.362 & -1.32 & -0.66 & -0.67 & 0.03 \\
\hline 1904 & -1.43 & -0.70 & -0.72 & 0.07 \\
\hline 1422 & -1.40 & -0.68 & -0.72 & 0.11 \\
\hline 191.52 & -1.53 & -0.75 & -0.78 & 0.10 \\
\hline 1452 & -1.61 & -0.78 & -0.83 & 0.01 \\
\hline 612 & -1.44 & -0.70 & -0.73 & 0.08 \\
\hline 102.3822 & -1.30 & -0.64 & -0.66 & 0.15 \\
\hline 59.642 & -1.52 & -0.75 & -0.77 & 0.01 \\
\hline 99.43 & -1.33 & -0.64 & -0.70 & 0.07 \\
\hline 68.162 & -1.24 & -0.61 & -0.64 & 0.01 \\
\hline 68.162 & -1.27 & -0.60 & -0.68 & 0.01 \\
\hline 107.212 & -1.49 & -0.72 & -0.78 & 0.04 \\
\hline 72.52 & -1.55 & -0.76 & -0.79 & 0.18 \\
\hline 89.62 & -1.36 & -0.64 & -0.70 & 0.06 \\
\hline 169.62 & -1.27 & -0.63 & -0.64 & 0.04 \\
\hline 762 & -1.24 & -0.60 & -0.63 & 0.01 \\
\hline 1553 & -1.62 & -0.82 & -0.80 & 0.19 \\
\hline 852 & -1.24 & -0.60 & -0.63 & 0.39 \\
\hline 115.842 & -1.44 & -0.74 & -0.69 & 0.01 \\
\hline 115.843 & -1.47 & -0.74 & -0.72 & 0.03 \\
\hline 115.842 & -1.44 & -0.73 & -0.72 & 0.01 \\
\hline 115.844 & -1.54 & -0.82 & -0.73 & 0.04 \\
\hline 115.843 & -1.50 & -0.76 & -0.75 & 0.04 \\
\hline 115.844 & -1.54 & -0.80 & -0.75 & 0.04 \\
\hline 115.842 & -1.66 & -0.88 & -0.78 & 0.08 \\
\hline 115.842 & -1.27 & -0.62 & -0.65 & 0.02 \\
\hline 115.842 & -1.26 & -0.62 & -0.64 & 0.08 \\
\hline 115.842 & -1.35 & -0.69 & -0.66 & 0.15 \\
\hline 115.842 & -1.35 & -0.69 & -0.67 & 0.16 \\
\hline 115.842 & -1.36 & -0.67 & -0.69 & 0.05 \\
\hline 115.842 & -1.34 & -0.66 & -0.69 & 0.09 \\
\hline 115.842 & -1.37 & -0.70 & -0.67 & 0.03 \\
\hline 115.842 & -1.36 & -0.67 & -0.68 & 0.17 \\
\hline 115.842 & -1.33 & -0.67 & -0.67 & 0.00 \\
\hline 115.845 & -1.36 & -0.66 & -0.70 & 0.17 \\
\hline 99.43 & -1.60 & -0.80 & -0.81 & 0.08 \\
\hline 99.43 & -1.62 & -0.79 & -0.83 & 0.04 \\
\hline 99.43 & -1.60 & -0.80 & -0.79 & 0.05 \\
\hline 99.43 & -1.57 & -0.79 & -0.78 & 0.04 \\
\hline 99.43 & -1.57 & -0.79 & -0.78 & 0.04 \\
\hline 99.43 & -1.61 & -0.81 & -0.81 & 0.07 \\
\hline 99.43 & -1.61 & -0.81 & -0.80 & 0.10 \\
\hline 99.44 & -1.66 & -0.82 & -0.83 & 0.07 \\
\hline 99.44 & -1.74 & -0.87 & -0.87 & 0.03 \\
\hline 99.43 & -1.43 & -0.70 & -0.72 & 0.05 \\
\hline 99.45 & -1.53 & -0.76 & -0.77 & 0.12 \\
\hline 99.43 & -1.38 & -0.69 & -0.69 & 0.11 \\
\hline
\end{tabular}




$\begin{array}{rrrrrr} & 99.44 & -1.59 & -0.80 & -0.79 & 0.09 \\ & 99.44 & -1.37 & -0.67 & -0.68 & 0.08 \\ \text { na } & 4 & -1.43 & -0.71 & -0.72 & 0.02 \\ \text { na } & 4 & -1.38 & -0.69 & -0.68 & 0.06 \\ \text { na } & 3 & -1.49 & -0.73 & -0.75 & 0.06 \\ \text { na } & 3 & -1.62 & -0.79 & -0.82 & 0.04\end{array}$


rel to SRM915a

2 s.d. $\delta^{43 / 42} \mathrm{Ca} \quad 2$ s.d. $\delta^{44 / 43} \mathrm{Ca} \quad$ Mean $\delta^{44 / 42} \mathrm{Ca}$

0.08

0.01

$-0.70$

0.01

0.02

$-0.80$

0.05

0.05

$-0.91$

0.04

0.10

$-0.88$

0.03

0.14

$-1.02$

0.08

0.06

$-1.09$

0.10

0.00

$-0.92$

0.09

0.06

$-0.79$

0.01

0.01

$-1.00$

0.01

0.07

$-0.82$

0.05

0.02

$-0.73$

0.00

0.01

$-0.75$

0.06

0.02

$-0.97$

0.07

0.12

$-1.03$

0.03

0.00

$-0.84$

0.04

0.09

$-0.75$

0.01

0.01

$-0.72$

0.12

0.11

$-1.10$

0.22

0.16

$-0.72$

0.04

0.03

$-0.92$

0.08

0.03

$-0.95$

0.04

0.04

$-0.92$

0.07

0.05

$-1.03$

0.04

0.02

$-0.98$

0.06

0.07

$-1.02$

0.01

0.07

$-1.14$

0.06

0.01

$-0.75$

0.06

0.02

$-0.74$

0.08

0.06

$-0.83$

0.00

0.09

$-0.83$

0.01

0.03

$-0.84$

0.10

0.00

$-0.82$

0.10

0.07

$-0.85$

0.14

0.01

$-0.84$

0.03

0.00

$-0.81$

0.09

0.09

$-0.84$

0.04

0.03

$-1.08$

$-1.10$

$-1.08$

0.06

0.07

$-1.05$

0.02

0.08

$-1.05$

0.04

0.01

$-1.09$

0.04

0.06

$-1.09$

0.08

0.05

$-1.14$

0.03

0.01

$-1.22$

0.03

0.02

$-0.91$

0.09

0.04

$-1.01$

0.07

0.05

$-0.86$ 


$\begin{array}{lll}0.07 & 0.02 & -1.07 \\ 0.05 & 0.07 & -0.85 \\ 0.02 & 0.04 & -0.92 \\ 0.07 & 0.02 & -0.87 \\ 0.04 & 0.06 & -0.98 \\ 0.02 & 0.04 & -1.10\end{array}$




\begin{tabular}{|c|c|c|c|c|c|}
\hline Collection id & Lab name & Origin & Genus & Species & Tissue \\
\hline UCBL-FSL 451.409 & AJ M1-1 & Jaurens & Rangifer & tarandus & enamel \\
\hline FSL 451.409 & AJ M1-2 & Jaurens & Rangifer & tarandus & enamel \\
\hline FSL 451.409 & AJ M1-3 & Jaurens & Rangifer & tarandus & enamel \\
\hline FSL 451.409 & AJ M2-1 & Jaurens & Rangifer & tarandus & enamel \\
\hline FSL 451.409 & AJ M2-2 & Jaurens & Rangifer & tarandus & enamel \\
\hline FSL 451.409 & AJ M2-3 & Jaurens & Rangifer & tarandus & enamel \\
\hline FSL 451.409 & AJ M3-1 & Jaurens & Rangifer & tarandus & enamel \\
\hline FSL 451.409 & AJ M3-2 & Jaurens & Rangifer & tarandus & enamel \\
\hline FSL 451.409 & AJ M3-3 & Jaurens & Rangifer & tarandus & enamel \\
\hline FSL 451.409 & AJ os & Jaurens & Rangifer & tarandus & mandibule bone \\
\hline FSL 451.409 & AJ P3-1 & Jaurens & Rangifer & tarandus & enamel \\
\hline FSL 451.409 & AJ P3-2 & Jaurens & Rangifer & tarandus & enamel \\
\hline FSL 451.409 & AJ P3-3 & Jaurens & Rangifer & tarandus & enamel \\
\hline FSL 451.398 & ISO DP4-1 & Jaurens & Rangifer & tarandus & enamel \\
\hline FSL 451.398 & ISO DP4-5 & Jaurens & Rangifer & tarandus & enamel \\
\hline FSL 451.384 & ISO M1-1 & Jaurens & Rangifer & tarandus & enamel \\
\hline FSL 451.384 & ISO M1-2 & Jaurens & Rangifer & tarandus & enamel \\
\hline FSL 451.384 & ISO M1-3 & Jaurens & Rangifer & tarandus & enamel \\
\hline FSL 451.384 & ISO M1-4 & Jaurens & Rangifer & tarandus & enamel \\
\hline FSL 451.384 & ISO M1-5 & Jaurens & Rangifer & tarandus & enamel \\
\hline FSL 451.384 & ISO M1-6 & Jaurens & Rangifer & tarandus & enamel \\
\hline FSL 451.384 & ISO M1-7 & Jaurens & Rangifer & tarandus & enamel \\
\hline FSL 451.389 & JVJ DP4-1 & Jaurens & Rangifer & tarandus & enamel \\
\hline FSL 451.389 & JVJ DP4-2 & Jaurens & Rangifer & tarandus & enamel \\
\hline FSL 451.389 & JVJ DP4-3 & Jaurens & Rangifer & tarandus & enamel \\
\hline FSL 451.389 & JVJ M1-1 & Jaurens & Rangifer & tarandus & enamel \\
\hline FSL 451.389 & JVJ M1-2 & Jaurens & Rangifer & tarandus & enamel \\
\hline FSL 451.389 & JVJ M1-3 & Jaurens & Rangifer & tarandus & enamel \\
\hline FSL 451.389 & JVJ M1-4 & Jaurens & Rangifer & tarandus & enamel \\
\hline FSL 451.389 & JVJ M1-5 & Jaurens & Rangifer & tarandus & enamel \\
\hline FSL 451.389 & JVJ M1-6 & Jaurens & Rangifer & tarandus & enamel \\
\hline FSL 451.389 & JVJ M2-1 & Jaurens & Rangifer & tarandus & enamel \\
\hline FSL 451.389 & JVJ os & Jaurens & Rangifer & tarandus & mandibular bone \\
\hline
\end{tabular}




\begin{tabular}{|c|c|c|c|c|c|}
\hline \multirow{2}{*}{ Sampling technique } & \multirow{2}{*}{ n } & & & \multicolumn{2}{|c|}{ rel to ICP Ca Lyon } \\
\hline & & Mean $\delta^{44 / 42} \mathrm{Ca}$ & Mean $\delta^{43 / 42} \mathrm{Ca}$ & Mean $\delta^{44 / 43} \mathrm{Ca}$ & 2 s.d. $\delta^{44 / 42} \mathrm{Ca}$ \\
\hline outer-drilling procedure & 3 & -1.52 & -0.82 & -0.71 & 0.09 \\
\hline outer-drilling procedure & 3 & -1.43 & -0.75 & -0.67 & 0.06 \\
\hline outer-drilling procedure & 3 & -1.55 & -0.83 & -0.71 & 0.05 \\
\hline outer-drilling procedure & 3 & -1.67 & -0.88 & -0.78 & 0.02 \\
\hline outer-drilling procedure & 3 & -1.62 & -0.84 & -0.78 & 0.06 \\
\hline outer-drilling procedure & 3 & -1.48 & -0.74 & -0.73 & 0.01 \\
\hline outer-drilling procedure & 3 & -1.64 & -0.89 & -0.76 & 0.04 \\
\hline outer-drilling procedure & 3 & -1.48 & -0.74 & -0.75 & 0.03 \\
\hline outer-drilling procedure & 3 & -1.47 & -0.77 & -0.71 & 0.04 \\
\hline outer-drilling procedure & 5 & -1.00 & -0.49 & -0.50 & 0.14 \\
\hline outer-drilling procedure & 3 & -1.68 & -0.87 & -0.80 & 0.01 \\
\hline outer-drilling procedure & 3 & -1.61 & -0.84 & -0.76 & 0.04 \\
\hline outer-drilling procedure & 3 & -1.49 & -0.75 & -0.75 & 0.09 \\
\hline edge-drilling procedure & 2 & -1.90 & -0.97 & -0.93 & 0.07 \\
\hline edge-drilling procedure & 3 & -1.74 & -0.90 & -0.84 & 0.05 \\
\hline edge-drilling procedure & 4 & -1.48 & -0.75 & -0.73 & 0.08 \\
\hline edge-drilling procedure & 4 & -1.39 & -0.71 & -0.68 & 0.09 \\
\hline edge-drilling procedure & 2 & -1.55 & -0.76 & -0.76 & 0.05 \\
\hline edge-drilling procedure & 2 & -1.57 & -0.81 & -0.77 & 0.07 \\
\hline edge-drilling procedure & 3 & -1.68 & -0.84 & -0.84 & 0.09 \\
\hline edge-drilling procedure & 3 & -1.65 & -0.83 & -0.81 & 0.04 \\
\hline edge-drilling procedure & 3 & -1.85 & -0.96 & -0.90 & 0.09 \\
\hline outer-drilling procedure & 3 & -1.95 & -1.03 & -0.92 & 0.07 \\
\hline outer-drilling procedure & 3 & -1.91 & -0.97 & -0.92 & 0.03 \\
\hline outer-drilling procedure & 3 & -1.97 & -0.98 & -0.99 & 0.10 \\
\hline outer-drilling procedure & 3 & -1.21 & -0.62 & -0.60 & 0.03 \\
\hline outer-drilling procedure & 3 & -1.68 & -0.89 & -0.80 & 0.07 \\
\hline outer-drilling procedure & 3 & -1.96 & -1.05 & -0.92 & 0.06 \\
\hline outer-drilling procedure & 2 & -1.68 & -0.86 & -0.82 & 0.03 \\
\hline outer-drilling procedure & 2 & -1.75 & -0.89 & -0.85 & 0.07 \\
\hline outer-drilling procedure & 2 & -2.03 & -1.03 & -0.99 & 0.08 \\
\hline outer-drilling procedure & 4 & -1.52 & -0.76 & -0.75 & 0.15 \\
\hline outer-drilling procedure & 3 & -0.94 & -0.47 & -0.48 & 0.17 \\
\hline
\end{tabular}


rel to SRM915a

2 s.d. $\delta^{43 / 42} \mathrm{Ca} \quad 2$ s.d. $\delta^{44 / 43} \mathrm{Ca} \quad$ Mean $\delta^{44 / 42} \mathrm{Ca}$

0.01

0.14

0.13

0.08

0.10

0.01

0.08

0.03

0.04

0.10

0.04

0.04

0.15

0.10

0.04

0.06

0.12

0.05

0.02

0.03

0.07

0.07

0.05

0.01

0.12

0.06

0.12

0.06

0.03

0.02

0.10

0.12

0.09
0.08

0.08

0.15

0.11

0.02

0.05

0.06

0.05

0.04

0.06

0.08

0.04

0.07

0.03

0.04

0.07

0.04

0.02

0.09

0.04

0.04

0.06

0.04

0.04

0.02

0.07

0.07

0.10

0.02

0.07

0.01

0.06

0.08
$-1.00$

$-0.92$

$-1.03$

$-1.15$

$-1.10$

$-0.96$

$-1.13$

$-0.97$

$-0.95$

$-0.48$

$-1.16$

$-1.09$

$-0.98$

$-1.38$

$-1.22$

$-0.96$

$-0.87$

$-1.03$

$-1.05$

$-1.17$

$-1.13$

$-1.34$

$-1.43$

$-1.39$

$-1.45$

$-0.69$

$-1.16$

$-1.44$

$-1.16$

$-1.23$

$-1.51$

$-1.00$

$-0.42$ 


$\begin{array}{lll}\begin{array}{l}\text { Standard name } \\ \text { SRM1486 }\end{array} & \text { Provider } & \text { Study } \\ & \text { NIST } & \text { this study } \\ & \text { Martin et al. } 2018 \\ & \text { Tacail et al. } 2017 \\ & \text { Tacail et al. } 2016 \\ & \text { Heuser and Eisenhauer } 2008 \\ & \text { this study } \\ & \text { Martin et al. } 2015 \\ \text { IAPSO } & \text { OSIL } & \text { Tacail et al. 2014 } \\ & \text { Compiled in Martin et al. } 2015 \text { from } 16 \text { studies }\end{array}$

Standard conversions

All standards and datasets from the literature expressed in $\delta^{44 / 40} \mathrm{C}$ a values were converted to $\delta^{44 / 42} \mathrm{C}$ The constant difference of $-0.518 \pm 0.025 \%$ o between standards measured against SRM915a vers। 


$\begin{array}{lll}\mathrm{n} & \delta^{44 / 42} \mathrm{Ca}_{\text {ICP Ca Lyon }} & 2 \text { s.d. } \\ 88 & -1.00 & 0.07 \\ 101 & -1.05 & 0.13 \\ 147 & -1.03 & 0.12 \\ 120 & -1.03 & 0.13 \\ 142 & -1.02 & 0.12 \\ 14 & 0.38 & 0.06 \\ 5 & 0.41 & 0.12 \\ 2 & 0.41 & 0.06 \\ - & 0.41 & 0.07\end{array}$

Za by dividing by 2.048 , as calculated using the exponential mass dependent fractionation law (suppl $\epsilon$ us ICP Ca Lyon (supplementaries from Martin et al. 2018) was used to calculate the corresponding iso 
?mentaries from Martin et al. 2018).

itope compositions of international standards from the literature with respect to ICP Ca Lyon. 


$\begin{array}{lllllll}\text { Collection id } & \text { Lab name } & \text { Origin } & \text { Genus } & \text { Species } & \text { sample type } & \text { ca [\%] } \\ \text { MNHL-50002207 } & \text { SPB B1 } & \text { Europe } & \text { Cervus } & \text { elaphus } & \text { antler bone } & 14.56 \\ \text { MNHL-50002207 } & \text { SPB B2 } & \text { Europe } & \text { Cervus } & \text { elaphus } & \text { antler bone } & 8.99 \\ \text { MNHL-50002207 } & \text { SPB B3 } & \text { Europe } & \text { Cervus } & \text { elaphus } & \text { antler bone } & 12.43 \\ \text { MNHL-50002207 } & \text { SPB os } & \text { Europe } & \text { Cervus } & \text { elaphus } & \text { mandibular bone } & 22.99 \\ \text { FSL 451.409 os } & \text { AJ os } & \text { Jaurens } & \text { Rangifer } & \text { tarandus } & \text { mandibular bone } & 27.87 \\ \text { FS 451.389 os } & \text { JVJ os } & \text { Jaurens } & \text { Rangifer } & \text { tarandus } & \text { mandibular bone } & 27.32 \\ \text { UP-15CE3734 } & \text { JVB os } & \text { Bauges } & \text { Cervus } & \text { elaphus } & \text { mandibular bone } & 21.29 \\ \text { AB F } & \text { AB F } & \text { Bauges } & & & \text { grass } & 1.83 \\ \text { JVB F } & \text { JVB F } & \text { Bauges } & & & \text { grass } & 0.99\end{array}$

${ }^{*}$ : below detection limit 


\begin{tabular}{llllll}
\hline $\mathrm{p}[\%]$ & fe $[\mathrm{ppm}]$ & $\mathrm{s}[\mathrm{ppm}]$ & al $[\mathrm{ppm}]$ & ba $[\mathrm{ppm}]$ & $\mathrm{k}[\mathrm{ppm}]$ \\
7.83 & $*$ & 6100.1 & $*$ & 50.1 & $*$ \\
5.10 & $*$ & 11481.3 & $*$ & 61.0 & 2933.5 \\
6.61 & $*$ & 8465.3 & $*$ & 39.6 & 1098.6 \\
11.86 & $*$ & 8969.5 & $*$ & 87.7 & 176.8 \\
13.49 & 5408.1 & 2250.0 & 1838.7 & 161.7 & $*$ \\
13.71 & $*$ & 2306.2 & 1518.7 & 172.8 & $*$ \\
11.56 & $*$ & 2181.3 & $*$ & 98.7 & 387.0 \\
0.54 & 313.1 & 1554.3 & 223.5 & 35.4 & 1298.1 \\
0.50 & 279.6 & 2126.6 & $*$ & 8.8 & 1419.5
\end{tabular}




\begin{tabular}{llllll}
\hline $\mathrm{mg}[\mathrm{ppm}]$ & $\mathrm{mn}[\mathrm{ppm}]$ & $\mathrm{na}[\mathrm{ppm}]$ & $\mathrm{sr}[\mathrm{ppm}]$ & y $[\mathrm{ppm}]$ & la $[\mathrm{ppm}]$ \\
1953.0 & 13.5 & 3994.7 & 116.7 & $*$ & 9.1 \\
1800.2 & 11.8 & 11011.2 & 58.4 & $*$ & 8.7 \\
2978.1 & 2.5 & 7272.7 & 57.7 & $*$ & 5.4 \\
3876.6 & 13.2 & 7861.5 & 126.0 & $*$ & 4.9 \\
658.5 & 1696.6 & 3256.0 & 109.5 & 46.8 & 35.7 \\
638.9 & 15.1 & 3150.4 & 119.5 & 14.3 & 18.6 \\
6580.1 & 1.0 & 6996.0 & 110.8 & $*$ & 5.7 \\
1095.1 & 219.6 & 2965.4 & 23.2 & $*$ & 1.4 \\
826.5 & 30.7 & 4642.3 & 21.6 & $*$ & 1.4
\end{tabular}




$\begin{array}{lllllll}\text { ce [ppm] } & \operatorname{pr}[\mathrm{ppm}] & \mathrm{nd}[\mathrm{ppm}] & \mathrm{sm}[\mathrm{ppm}] & \mathrm{eu}[\mathrm{ppm}] & \mathrm{gd}[\mathrm{ppm}] & \text { tb [ppm] } \\ * & * & * & * & * & * & * \\ * & * & * & * & * & * & * \\ * & * & * & * & * & * & * \\ * & * & * & * & * & * & * \\ 12.1 & 4.8 & 23.3 & 3.6 & 0.9 & 4.1 & * \\ 1.6 & 1.5 & 7.6 & 1.0 & * & 1.3 & * \\ * & * & * & * & * & * & * \\ * & * & * & * & * & * & * \\ * & * & * & * & * & * & *\end{array}$




$\begin{array}{llllll}\text { dy [ppm] } & \text { ho [ppm] } & \text { er [ppm] } & \text { tm [ppm] } & \text { yb [ppm] } & \text { lu [ppm] } \\ * & * & * & * & * & * \\ * & * & * & * & * & * \\ * & * & * & * & * & * \\ * & * & * & * & * & * \\ 3.0 & 0.8 & 2.3 & * & 2.0 & * \\ * & * & * & * & * & * \\ * & * & * & * & * & * \\ * & * & * & * & * & * \\ * & * & * & * & * & *\end{array}$

